\title{
Second near-infrared
}

\section{photothermal-amplified immunotherapy using photoactivatable composite nanostimulators}

\author{
Haitao Sun ${ }^{1 \dagger}$, Tianzhu Yu ${ }^{1 \dagger}$, Xin $\mathrm{Li}^{3 \dagger}$, Yangyang Lei ${ }^{1}$, Jianke Li ${ }^{1}$, Xiuhui Wang ${ }^{4^{*}}$, Peike Peng ${ }^{5^{*}}$, Dalong $\mathrm{Ni}^{6}$, \\ Xiaolin Wang ${ }^{1 *}$ and Yu Luo ${ }^{2^{*}}$ (D)
}

\begin{abstract}
Background: The construction of a nanoimmune controlled-release system that spatiotemporally recognizes tumor lesions and stimulates the immune system response step by step is one of the most potent cancer treatment strategies for improving the sensitivity of immunotherapy response.

Results: Here, a composite nanostimulator (CNS) was constructed for the release of second near-infrared (NIR-II) photothermal-mediated immune agents, thereby achieving spatiotemporally controllable photothermal-synergized immunotherapy. CNS nanoparticles comprise thermosensitive liposomes as an outer shell and are internally loaded with a NIR-II photothermal agent, copper sulfide (CuS), toll-like receptor-9 (TLR-9) agonist, cytosine-phospho-guanine oligodeoxynucleotides, and programmed death-ligand 1 (PD-L1) inhibitors (JQ1). Following NIR-II photoirradiation, CuS enabled the rapid elevation of localized temperature, achieving tumor ablation and induction of immunogenic cell death (ICD) as well as disruption of the lipid shell, enabling the precise release of two immune-therapeutical drugs in the tumor region. Combining ICD, TLR-9 stimulation, and inhibited expression of PD-L1 allows the subsequent enhancement of dendritic cell maturation and increases infiltration of cytotoxic T lymphocytes, facilitating regional antitumor immune responses.
\end{abstract}

Conclusion: CNS nanoparticle-mediated photothermal-synergized immunotherapy efficiently suppressed the growth of primary and distant tumors in two mouse models and prevented pulmonary metastasis. This study thus provides a novel sight into photo-controllably safe and efficient immunotherapy.

\footnotetext{
*Correspondence: blackrabbit@shu.edu.cn; pengpeike@shutcm.edu.cn; fduwangxiaolin@hotmail.com; yuluo@sues.edu.cn

${ }^{\dagger}$ Haitao Sun, Tianzhu Yu and Xin Li contributed equally to this work

${ }^{1}$ Department of Interventional Radiology, Zhongshan Hospital, Fudan University, Shanghai Institute of Medical Imaging, No. 180 Fenglin Road, Xuhui District, Shanghai 200032, China

2 Shanghai Engineering Technology Research Center for Pharmaceutical Intelligent Equipment, Shanghai Frontiers Science Research Center for Druggability of Cardiovascular noncoding RNA, Institute for Frontier Medical Technology, School of Chemistry and Chemical Engineering, Shanghai University of Engineering Science, No. 333 Longteng Road, Shanghai 201620, People's Republic of China

${ }^{4}$ Institute of Translational Medicine, Shanghai University, Shanghai 200011, People's Republic of China

${ }^{5}$ School of Basic Medical Sciences, Shanghai University of Traditional Chinese Medicine, Shanghai, People's Republic of China

Full list of author information is available at the end of the article
} permits use, sharing, adaptation, distribution and reproduction in any medium or format, as long as you give appropriate credit to the original author(s) and the source, provide a link to the Creative Commons licence, and indicate if changes were made. The images or other third party material in this article are included in the article's Creative Commons licence, unless indicated otherwise in a credit line to the material. If material is not included in the article's Creative Commons licence and your intended use is not permitted by statutory regulation or exceeds the permitted use, you will need to obtain permission directly from the copyright holder. To view a copy of this licence, visit http://creativecommons.org/licenses/by/4.0/. The Creative Commons Public Domain Dedication waiver (http://creativeco mmons.org/publicdomain/zero/1.0/) applies to the data made available in this article, unless otherwise stated in a credit line to the data. 
Keywords: Second near-infrared light, Nanostimulators, Precise controlled release, Cancer immunotherapy, Photothermal therapy

\section{Graphical Abstract}

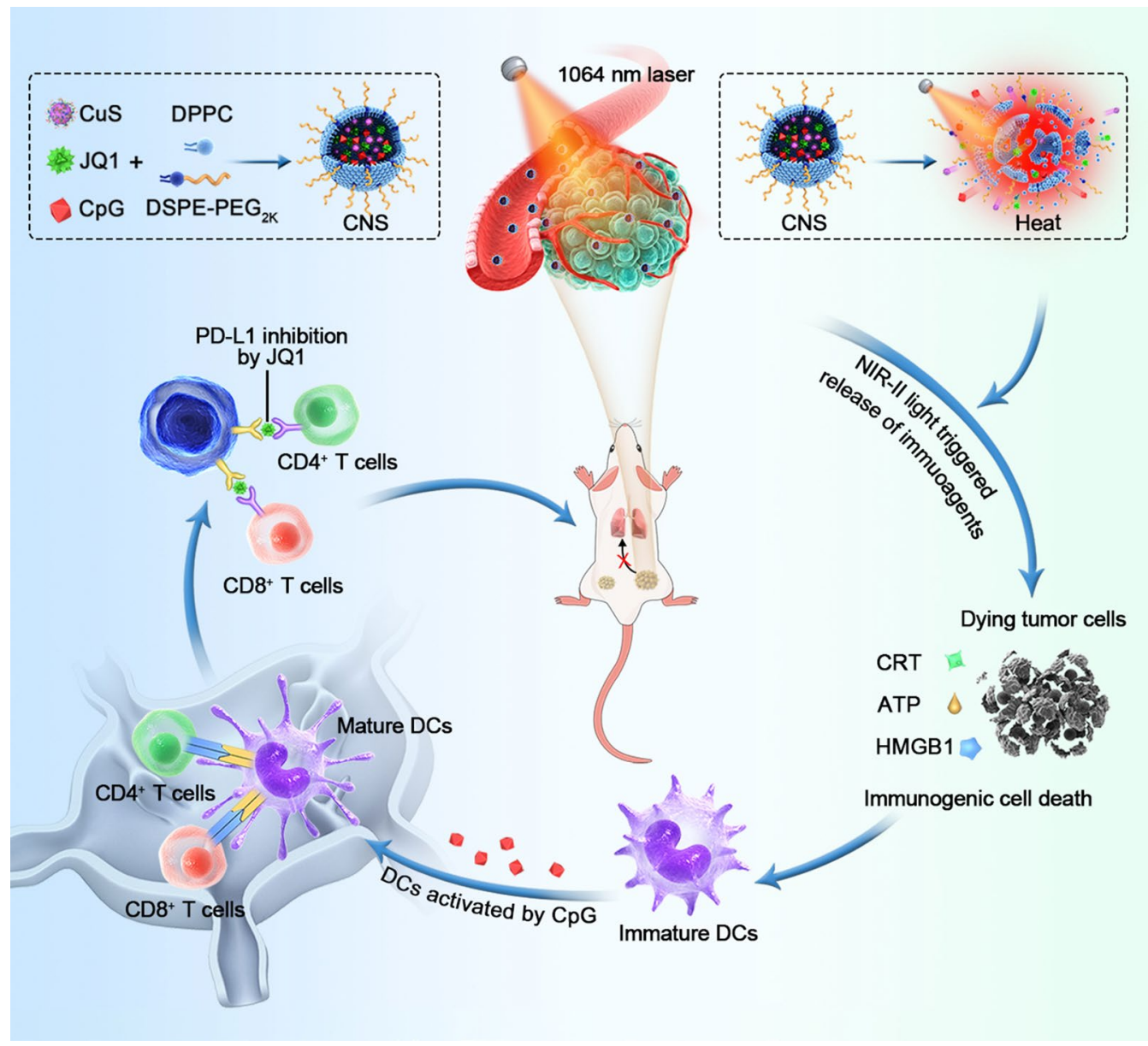

\section{Background}

Tumor immunotherapy that mobilizes immune cells to fight malignant tumors is a promising therapeutic approach [1,2]. Diverse immunotherapy strategies, such as the modulation of immune checkpoint inhibitors (ICBs) against programmed death/ligand 1 (PD-1/ PD-L1) [3, 4], cytotoxic T lymphocyte-associated protein 4 (CTLA-4) [5, 6], and adoptive T cell transfer [7-9], have shown satisfactory prospects in clinical studies. Several immune drugs, such as PD-L1 inhibitors and CTLA-4 inhibitors, have been approved by the U.S. Food and Drug Administration (FDA) and successfully commercialized [10]. However, immunotherapy for clinical application has only benefited a small proportion of specific tumor patients due to a low immune response $[1,11]$. For instance, tumor patients with an abnormal immune status rarely benefit from checkpoint blockade treatment
[12]. Moreover, patients with solid tumors cannot easily be treated using chimeric antigen receptor-redirected $\mathrm{T}$ lymphocytes, which only benefit some patients with hematological cancers [13-15]. Other major limiting factors of tumor immunotherapy include serious immunerelated systemic toxicity caused by the action of immune drugs in normal tissues and the low efficiency of immune activation in solid tumors [16]. Therefore, the use of clinical immunotherapy with higher efficiency and safety is necessary.

Nanomedicines combining nanotechnology and immunotherapy have shown the potential to improve the efficacy of immunotherapy and minimize toxic side effects $[17,18]$. The therapeutic efficiency of nanomedicine-mediated immunotherapy can be strengthened by optimization of pharmacokinetics and toxicity of traditional immune drugs and improving the intratumoral 
concentration of drugs [19, 20]. Additionally, immunotherapeutic nanomedicines remolded with nanoengineering technology can also improve the efficiency of immune activation via several other mechanisms, such as controlling the timing of immune drug release and/ or activation [21], actively targeting immune cells [22, 23], and optimizing the efficiency of drug internalization [24]. These nanomedicines can be designed to respond to external energy fields, such as light [25], ultrasound [26], and magnetic fields [27], thereby achieving the high spatial-temporally release of immune drugs in specific regions. Li et al. recently developed an activatable engineered immune device, which can be remotely controlled by near-infrared (NIR) light. In this scenario, NIR light excitation was used to break the photoresponsive linker, releasing active $\mathrm{CpG}$ oligonucleotides (ODNs) and precisely activating local intratumoral inflammation without obvious systemic side effects [28]. Therefore, steerable nanomedicines that precisely and safely control cancer immunotherapy are highly promising.

Photothermal therapy (PTT) can act based on the host-guest effect between the laser and material in addition to its familiar high-temporal resolution regulation of drug release and photothermal ablation of tumors [2931]. The nanomedicine-mediated photothermal effect can ablate tumor cell release of tumor antigens, damageassociated molecular patterns (DAMPs), and immunostimulatory elements, which enable the maturation of dendritic cells (DCs) and activation of immune cells [32-34]. In addition to synergistic effects with immunotherapy, the photothermal effect generated by PTT can also be used to trigger the release of immune agents from nanocarriers by melting the temperature-responsive chemical bonds or nanocarrier structures [35]. Thus, PTT-synergized immunotherapy has great potential to achieve more accurate, effective, and safe immune activation against tumor growth. Sun et al, recently constructed an injectable lipid gel encapsulating a photothermal agent (IR820) and anti-PD-L1 antibody (andL1), which enabled the controllable release of PD-L1 in specific areas, achieving photothermal-assisted immunotherapy [36]. To date, the combined use of PTT with immunotherapy has mostly been based on the excitation of light in the first NIR window (NIR-I, 700-1000 nm), which has inherent limitations of relatively low tissue penetration depth $(\leq 1 \mathrm{~cm})$ [37]. Comparatively, in terms of light penetration, the light in the second NIR window (NIR-II, 1000-1700 nm) was elevated three to five-fold $(3-5 \mathrm{~cm})$ [38-40]. Phototoxicity analysis showed that the maximum permissible exposure (MPE) of NIR-II light for skin was improved compared with NIR-I light. For example, the MPE of $1064 \mathrm{~nm}$ NIR-II light $\left(1 \mathrm{~W} \mathrm{~cm}^{-2}\right)$ was around three-fold higher than that of $808 \mathrm{~nm}$ NIR-I light $\left(0.33 \mathrm{~cm}^{-2}\right)$ [41]. Therefore, NIR-II PTT-synergized immunotherapy may yield better immune-activating effects in the deeper tissues of patients with solid tumors [42]. However, few studies have investigated NIR-II PTTactivated immunotherapy.

In the present study, different types of novel NIRphotoactivated composite nanostimulator (CNS) were constructed for NIR-II photothermal-synergized immunotherapy. The CNS nanoparticles internally contained copper sulfide (CuS), a NIR-II photothermal conversion agent, two types of immune agent, CpG ODNs, a toll-like receptor-9 (TLR-9) agonist, and JQ1, a PD-L1 inhibitor, which was externally encapsulated by a temperaturesensitive lipid shell (Scheme 1). CuS nanoparticles have recently been considered to be excellent NIR-II photothermal conversion agents due to their obvious absorbance in the NIR-II window, high stability, and good biocompatibility, and have been applied to tumor treatment. The temperature-sensitive lipid shell consisted of thermally sensitive 1,2-dipalmitoyl-sn-glycerol-3-phosphocholine (DPPC) and 1,2-distearoyl-sn-glycero3-phosphoethanolamine-poly(ethylene glycol)2000 (DSPE-PEG ${ }_{2 \mathrm{k}}$ ), and could be melted at a relatively high temperature $\left(>41{ }^{\circ} \mathrm{C}\right.$, the phase transition temperature of DPPC), thereby releasing loaded immune drugs into a specific region [43,44]. CpG, which is a well-known immunoadjuvant studied in phase I-III trials, can facilitate the activation of DCs and enhance cytokine secretion by antigen-presenting cells (APCs) [45, 46]. JQ1, which is a bromodomain and extra terminal protein BRD4 inhibitor, was used to overcome immunological tolerance by downregulating the intratumoral expression of PD-L1 [47]. However, the clearance properties of CpG and potential drug toxicity and water insolubility of JQ1 are limited in their applications for tumor treatment. Thus, the present study used two immune drugs encapsulated in thermally-sensitive liposomes, which were intravenously administered for delivery into the tumor site without being prematurely cleared or released elsewhere. NIR-II photoexcitation of the tumor site enabled CNS-mediated NIR-II PTT to elevate the intratumoral temperature, leading to tumor ablation as well as ICD of tumor cells and releasing of immune-related molecules. Notably, PTT-mediated hyperthermia was able to disrupt the thermally-sensitive lipid layer for the spatiotemporally controllable release of immune agents in the tumor region. Combining ICD and stimulation of TLR-9 are potent promotors of DC maturation in tumor-draining lymph nodes, resulting in an adaptive antitumor immune response. JQ1 can further enhance the intratumoral infiltration of cytotoxic $\mathrm{T}$ lymphocytes via downregulation of PD-L1 expression to achieve a more robust antitumor immune activation. CNS nanoparticle-mediated 


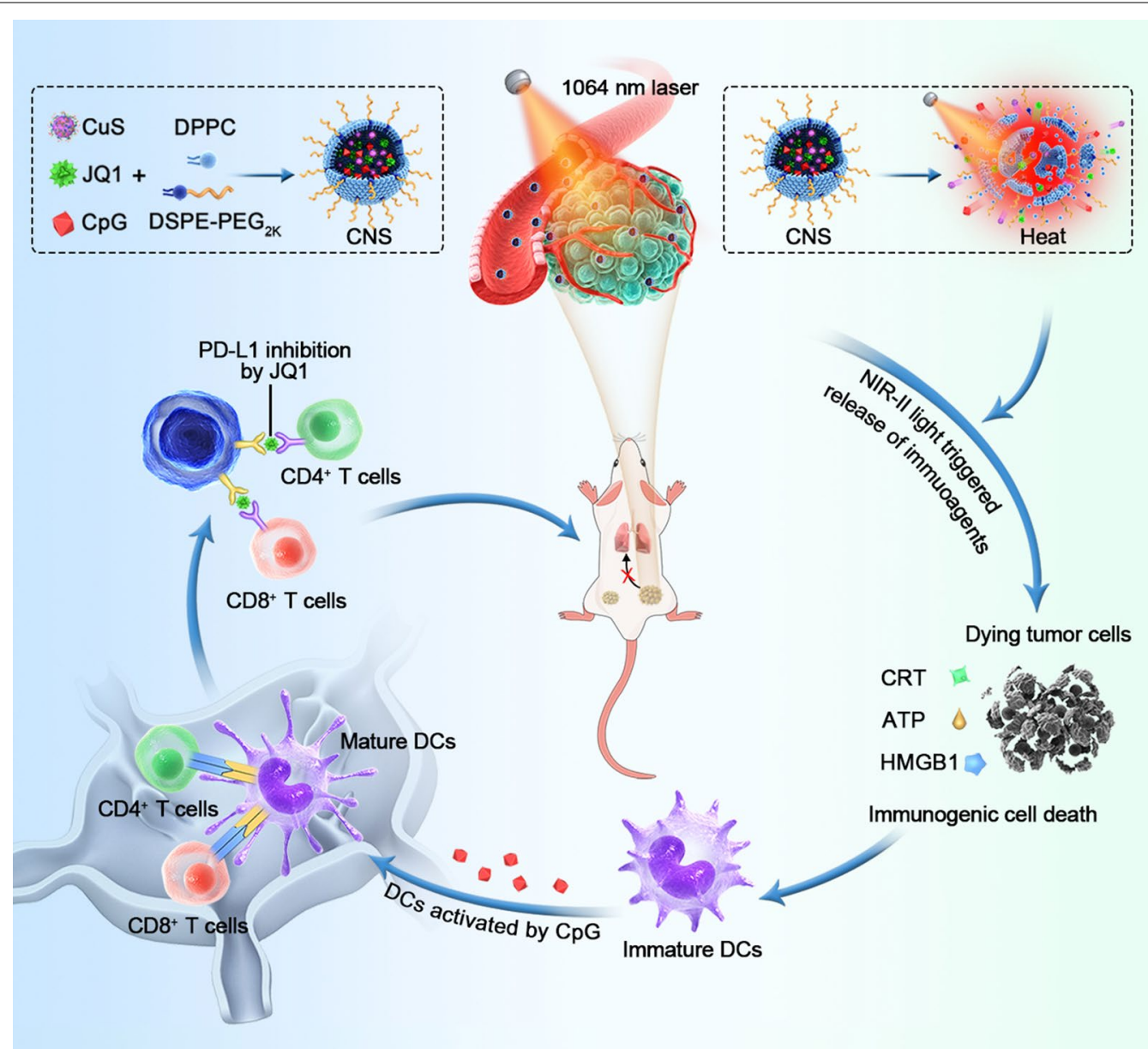

Scheme 1 Schematic illustration of NIR-II photoactivated CNSs for remotely controlling photothermal immunotherapy. The simplified synthesis of NIR-II photoactivated CNS and the immune activation cascade of CNS-mediated remotely controlled photothermal immunotherapy are shown

NIR-II photothermal-synergized immunotherapy not only efficiently suppressed the growth of both primary and distant tumors but also greatly inhibited pulmonary metastasis in a murine breast cancer model.

\section{Material and methods}

\section{Synthesis of BSA-CuS nanoparticles}

The synthetic process was briefly divided into three steps. First, $\mathrm{CuCl}_{2}(0.1 \mathrm{M})$ dispersed in $2 \mathrm{~mL}$ of ultrapure water was added dropwise into BSA $(250 \mathrm{mg})$ dispersed in $50 \mathrm{~mL}$ of ultrapure water and reacted for $3 \mathrm{~min}$. Then, $\mathrm{NaOH}(2 \mathrm{M})$ was rapidly infused into the mixed solution and stirred for $3 \mathrm{~min}$. Finally, $\mathrm{Na}_{2} \mathrm{~S}(0.5 \mathrm{M})$ dispersed in $0.8 \mathrm{~mL}$ ultrapure water was rapidly added to the mixed solution. The solution was mixed using magnetic stirring for $3 \mathrm{~h}$. The obtained BSA-CuS solution was purified by centrifugation at $12,000 \mathrm{rpm}$ for $5 \mathrm{~min}$. The supernatant was then dialyzed against water using a dialysis bag (molecular weight cutoff of 8-14 $\mathrm{kDa}$ ). The purified
BSA-CuS nanoparticles (referred to as $\mathrm{CuS}$ ) were then stored at $4{ }^{\circ} \mathrm{C}$ before use.

\section{Synthesis of photoactivated CNS}

$\mathrm{DSPE}-\mathrm{PEG}_{2 \mathrm{k}}$, DPPC, and JQ1 with a mass ratio of 5:25:1 were co-dissolved in $10 \mathrm{~mL}$ chloroform. The mixture solution was then evaporated to form a thin film using a rotary evaporator. Next, $20 \mathrm{~mL}$ of ultrapure water containing $\mathrm{CuS}(2 \mathrm{mg})$ and $\mathrm{CpG}(2 \mathrm{OD})$ was added into the thin film and stirred at $55^{\circ} \mathrm{C}$ for $1 \mathrm{~h}$. After the hydration process, the solution was sonicated by the ultrasonic cell pulverizer in ice bath conditions for $60 \mathrm{~min}$. The obtained solutions were then filtered using a $0.22-\mu \mathrm{m}$ PVDF syringe-driven filter (Millipore, Bedford, USA) and then purified using ultrafiltration (cutoff molecular weight of $50,000 \mathrm{Da}, 5000 \mathrm{rpm}$ ) three times to remove unloaded drugs. The obtained $\mathrm{CNS}_{\mathrm{D}}$ (CuS-CpG-JQ1@lipsome) was stored at $4{ }^{\circ} \mathrm{C}$ before use. $\mathrm{CNS}_{0}$ (CuS@lipsome), $\mathrm{CNS}_{\mathrm{C}}$ (CuS-CpG@lipsome), and CNS (CuS-JQ1@ 
lipsome) were synthesized using the same method. Additionally, ICG-loaded liposomes were constructed for cellular uptake assays in vitro and NIR fluorescence imaging in vivo. ICG@CNS ${ }_{D}$ was synthesized similarly using the hydration-sonication procedure. In brief, DSPE-PEG ${ }_{2 \mathrm{k}}$, DPPC, and JQ1 with a mass ratio of 5:25:1 were co-dissolved in chloroform. A thin film was obtained through a rotary evaporator. Then, $20 \mathrm{~mL}$ ultrapure water containing ICG (2 mg), CuS (2 mg), and CpG (2 OD) and was added into the above thin film, and stirred at $55^{\circ} \mathrm{C}$ for $1 \mathrm{~h}$. The subsequent synthesis method was the same as those of $\mathrm{CNS}_{\mathrm{D}}$. Similarly, ICG@CNS , ICG@CNS $_{\mathrm{C}}$, and ICG@CNS I $_{\text {I }}$ were also obtained through the same method.

The CNS nanoparticle morphologies were imaged using JEM 2100F transmission electron microscope. The DLS and zeta potential of the obtained CNS nanoparticles were analyzed using the Zetasizer Nano series. UV-vis spectrophotometry and HPLC were performed to investigate the loading capacity (LC) and encapsulation efficiency (EE) of CuS, CpG (Cy5.5-CpG, absorbance peak $=650 \mathrm{~nm})$ and JQ1 $\left(\lambda_{\mathrm{abs}}=260 \mathrm{~nm}\right.$, elution $\left.\sim 10 \mathrm{~min}\right)$ of $\mathrm{CNS}_{\mathrm{D}}$. The colloidal stability of $\mathrm{CNS}_{\mathrm{D}}$ nanoparticles was evaluated using the Zetasizer Nano series. $\mathrm{CNS}_{\mathrm{D}}$ dissolved in $1 \times$ PBS was continuously observed for 10 days, and the corresponding DLS and PDI of the nanoparticles were recorded every two days.

\section{Cellular uptake of CNS nanoparticles}

ICG-loaded CNS nanoparticles were used to study the uptake of nanoparticles in both Panc02 and 4T1 cells. First, the Panc02 cells were seeded in 12-well plates at a density of $2 \times 10^{5}$ per well overnight and then co-cultured with ICG@CNS , ICG@CNS $_{\mathrm{C}}$, ICG@CNS , and ICG@CNS ${ }_{\mathrm{D}}$ for $24 \mathrm{~h}\left(20 \mu \mathrm{g} \mathrm{mL}^{-1}\right.$ for all). Cells were then washed three times with PBS and collected to measure the intracellular fluorescence intensity of ICG via flow cytometry. Then, the uptake of nanoparticles in $4 \mathrm{~T} 1$ cells was conducted and analyzed as described above.

\section{Cytotoxicity assays and evaluation of therapeutic efficacy in vivo}

The safety performance of the nanoparticles was evaluated in vivo. Panc02 cells were plated in 96-well plates and cultured overnight and then co-cultured with $\mathrm{CNS}_{0}$, $\mathrm{CNS}_{\mathrm{C}}, \mathrm{CNS}_{\mathrm{I}}$, and $\mathrm{CNS}_{\mathrm{D}}$ at various $\mathrm{CuS}$ concentrations $(0$, $12.5,25,50$, and $100 \mu \mathrm{g} \mathrm{mL}^{-1}$ ) for $24 \mathrm{~h}$. The cells were then washed three times with PBS and the absorbance of each well was measured at $450 \mathrm{~nm}$ using a microplate reader to examine cell viability. The viabilities of various CNS nanoparticles and laser-treated cells were subsequently verified using CCK- 8 assays. Panc02 cells were incubated in 96-well plates overnight and then co-cultured with $\mathrm{CNS}_{0}, \mathrm{CNS}_{\mathrm{C}}, \mathrm{CNS}_{\mathrm{J}}$, and $\mathrm{CNS}_{\mathrm{D}}$ at various $\mathrm{CuS}$ concentrations $\left(0,12.5,25,50\right.$, and $\left.100 \mu \mathrm{g} \mathrm{mL}{ }^{-1}\right)$ for $24 \mathrm{~h}$. The cells were then rinsed three times with PBS and a new medium was added. Each well was irradiated using a $1064 \mathrm{~nm}$ laser $\left(1 \mathrm{~W} \mathrm{~cm}^{-2}\right)$ for $5 \mathrm{~min}$ and then cultured for $24 \mathrm{~h}$. Finally, the absorbance of each well was measured at $450 \mathrm{~nm}$ using a microplate reader.

\section{In vivo tumor accumulation of CNS nanoparticles}

Panc02 tumor-bearing C57BL/6 mice $(n=3)$ were systemically injected with $0.2 \mathrm{~mL}$ of $300 \mu \mathrm{g} / \mathrm{mL}$ CNS@ICG via tail-vein injection. The mice were imaged at different post-injection time points $(0,8,24$, and $36 \mathrm{~h})$ to determine the accumulation of CNS nanoparticles in the tumor. The tumors were imaged using the IVIS imaging system (excitation and emission at 710 and $790 \mathrm{~nm}$, respectively). The corresponding processing software (Living Image software) was performed to record images and calculate the fluorescence intensity of tumors at different time points.

\section{In vivo photothermal performance of CNS nanoparticles}

Panc02 tumor-bearing C57BL/6 mice were randomly divided into four groups $(n=3)$. The mice in each group were administered $300 \mu \mathrm{g} / \mathrm{mL}$ of $\mathrm{CNS}_{0}, \mathrm{CNS}_{\mathrm{C}}, \mathrm{CNS}_{\mathrm{T}}$, and $\mathrm{CNS}_{\mathrm{D}}$ via tail-vein injection $(0.2 \mathrm{~mL})$. Each primary tumor was then photoirradiation using a $1064 \mathrm{~nm}$ laser $\left(1 \mathrm{~W} \mathrm{~cm}^{-2}\right)$ for $5 \mathrm{~min}$ at $24 \mathrm{~h}$ post-injection. The thermal images and corresponding temperature of tumors were recorded using an infrared thermal camera (FLIR $225 \mathrm{~s}$ IR thermal).

In vivo curative effect assessment on Panc02 tumor models Panc02 tumor-bearing C57BL/6 mice were randomly divided into six groups: control (PBS); $\mathrm{CNS}_{0}+\mathrm{L}$; $\mathrm{CNS}_{\mathrm{C}}+\mathrm{L} ; \mathrm{CNS}_{\mathrm{J}}+\mathrm{L} ; \mathrm{CNS}_{\mathrm{D}}$; and $\mathrm{CNS}_{\mathrm{D}}+\mathrm{L}(\mathrm{n}=5)$. The mice in each group were intravenously administered with $0.2 \mathrm{~mL}$ PBS or $300 \mu \mathrm{g} / \mathrm{mL} \mathrm{CNS}_{0}, \mathrm{CNS}_{\mathrm{C}}, \mathrm{CNS}_{\mathrm{J}}$, and $\mathrm{CNS}_{\mathrm{D}}$. Then, each primary tumor was photoirradiation using a 1064-nm laser $\left(1 \mathrm{~W} \mathrm{~cm}^{-2}\right)$ for $5 \mathrm{~min}$ at $24 \mathrm{~h}$ postinjection. After the different treatments, the treatment efficacies were assessed by calculating the volumes of the primary and distant tumors every two days for 14 days. Meanwhile, the body weights of Panc02 tumor-bearing C57BL/6 mice were also recorded every two days for 14 days. Tumor volume (V) was calculated using the formula: $\mathrm{V}=$ length $\times$ width $^{2} / 2$, and the relative tumor volumes were calculated as $\mathrm{V} / \mathrm{V}_{0}$ (where $\mathrm{V}_{0}$ represents the original tumor volumes). On day 1 post-treatment, the primary tumors were examined for H\&E, TUNEL, and Ki-67 staining to evaluate the intratumoral treatment effect. On day 14 post-treatment, the mice in each group 
were euthanized and the corresponding tumor weights of both the primary and distant tumors were calculated.

\section{In vivo treatment and antimetastatic efficacy evaluation on 4T1 tumor models}

4T1 tumor-bearing Balb/c mice were randomly divided into six groups: control (PBS); $\mathrm{CNS}_{0}+\mathrm{L} ; \mathrm{CNS}_{\mathrm{C}}+\mathrm{L}$; $\mathrm{CNS}_{\mathrm{J}}+\mathrm{L} ; \mathrm{CNS}_{\mathrm{D}}$; and $\mathrm{CNS}_{\mathrm{D}}+\mathrm{L}(\mathrm{n}=5)$. The mice in each group were intravenously administered with $0.2 \mathrm{~mL}$ of PBS or $300 \mu \mathrm{g} / \mathrm{mL} \mathrm{CNS}_{0}, \mathrm{CNS}_{\mathrm{C}}, \mathrm{CNS}_{\text {, }}$, and $\mathrm{CNS}_{\mathrm{D}}$. Each primary tumor was then photoirradiation using a $1064 \mathrm{~nm}$ laser $\left(1 \mathrm{~W} \mathrm{~cm}^{-2}\right)$ for $5 \mathrm{~min}$ at $24 \mathrm{~h}$ postinjection. After the different treatments, the treatment efficacies were assessed by calculating the volumes of both primary and distant tumors every two days for 14 days. Meanwhile, the body weights of 4T1 tumor-bearing Balb/c mice were also recorded every two days for 14 days. Tumor volume $(\mathrm{V})$ was calculated using the formula: $\mathrm{V}=$ length $\times$ width $^{2} / 2$, and the relative tumor volumes were calculated as $\mathrm{V} / \mathrm{V}_{0}$ (where $\mathrm{V}_{0}$ represents the original tumor volumes). On day 1 post-treatment, the tumors were examined for $H \& E$ staining to evaluate the intratumoral treatment effects.

The mice in the different treatment groups $(n=3)$ were euthanized to collect lung tissue at 30 days posttreatment to study the antitumor lung metastasis of CNS nanoparticles. The metastatic nodules in the lungs were photographed and H\&E staining was performed.

\section{In vivo biocompatibility assessment of CNSD}

Panc02 tumor-bearing C57BL/6 mice in each group were sacrificed at the end of treatment. Major organs including the heart, liver, spleen, lung, and kidney were collected and examined by H\&E staining. The long-term biocompatibility of $\mathrm{CNS}_{\mathrm{D}}$ was also assessed in healthy female $\mathrm{C} 57 \mathrm{BL} / 6$ mice. The mice in the treated groups were intravenously injected with $200 \mu \mathrm{L}$ of $300 \mu \mathrm{g} / \mathrm{mL} \mathrm{CNS}_{\mathrm{D}}$. At day 0 and various post-injection time points (days 15 and 30), blood samples were examined for routine blood and biochemical analysis $(\mathrm{n}=3)$. The corresponding major organs (heart, liver, spleen, lung, and kidney) were also examined by $\mathrm{H} \& \mathrm{E}$ staining at 0,15 , and 30 days.

\section{Statistical analysis}

Data are shown as mean \pm standard deviation. One-way analysis of variance (ANOVA) with Tukey's multiple comparisons test was performed to analyze the statistical significance among different groups. Statistical significance was divided as three categories: *p $<0.05{ }^{* * *} \mathrm{p}<0.01$, and ${ }^{* * * *} \mathrm{p}<0.001$.

\section{Results and discussion}

\section{Synthesis and characterization of CNS}

Various photoactivated CNS loading agents were prepared using a film hydration method [48]. In brief, a thin film composed of DPPC (MW =734.0) and DSPE$\mathrm{PEG}_{2 \mathrm{k}}(\mathrm{MW}=2805.5)$ with a feeding mass ratio of 25:5 was synthesized and then hydrated with ultrapure water including CuS, JQ1, and CpG. Hydrophobic JQ1 and hydrophilic $\mathrm{CuS}$ and $\mathrm{CpG}$ were encapsulated into temperature-responsive liposomes through hydrophobic and $\pi-\pi$ stacking interactions. The EE of $\mathrm{CNS}_{\mathrm{D}}$ was $71.8 \%$ for $\mathrm{CuS}, 57.2 \%$ for JQ1, and $69.8 \%$ for $\mathrm{CpG}$, and the corresponding $\mathrm{LC}$ values were $4.3 \%, 1.7 \%$, and $0.1 \%$, respectively. Three control counterparts $\left(\mathrm{CNS}_{0}, \mathrm{CNS}_{\mathrm{C}}\right.$, and $\mathrm{CNS}_{\mathrm{J}}$ ) were simultaneously prepared using a similar process and used as a comparison.

As shown in the transmission electron microscopy (TEM) images, $\mathrm{CNS}_{\mathrm{D}}$ and the three control counterparts $\left(\mathrm{CNS}_{0}, \mathrm{CNS}_{\mathrm{C}}\right.$, and $\left.\mathrm{CNS}_{\mathrm{J}}\right)$ were quasi-spherical and showed a uniform size distribution (Fig. 1a). Dynamic light scattering (DLS) revealed that the hydrodynamic size of $\mathrm{CNS}_{\mathrm{D}}$ was approximately $31.3 \pm 1.4 \mathrm{~nm}$, which was slightly larger than that of $\mathrm{CNS}_{0}(25.1 \pm 1.1 \mathrm{~nm})$, $\mathrm{CNS}_{\mathrm{C}}(27.0 \pm 2.7 \mathrm{~nm})$, and $\mathrm{CNS}_{\mathrm{J}}(26.2 \pm 3.7 \mathrm{~nm})$ (Fig. 1b). Moreover, the polydispersity indexes (PDIs) of $\mathrm{CNS}_{0}$, $\mathrm{CNS}_{\mathrm{C}}, \mathrm{CNS}_{\text {, }}$, and $\mathrm{CNS}_{\mathrm{D}}$ were $0.23,0.22,0.24$, and 0.23 , respectively, suggesting good mono-dispersity of the four types of nanoparticles. The zeta potential was measured to investigate the surface charge of various prepared nanoparticles. Compared with $\mathrm{CNS}_{\mathrm{C}}(-28.9 \mathrm{mV}), \mathrm{CNS}_{\mathrm{D}}$ $(-23.4 \mathrm{mV})$ in $1 \times$ phosphate-buffered saline (PBS) showed an elevated surface charge, indicating successful JQ1 loading. Compared with $\mathrm{CNS}_{\mathrm{J}}(-20.9 \mathrm{mV}), \mathrm{CNS}_{\mathrm{D}}$ $(-23.4 \mathrm{mV})$ in $1 \times \mathrm{PBS}$ showed a reduced surface charge, indicating successful CpG ONDs encapsulation (Fig. 1c). $\mathrm{CNS}_{\mathrm{D}}$ and the three control counterparts $\left(\mathrm{CNS}_{0}, \mathrm{CNS}_{\mathrm{C}}\right.$, and $\mathrm{CNS}_{\mathrm{T}}$ ) showed similar peaks in the ultraviolet-visible (UV-vis) absorption spectrum, indicating the inappreciable affection of loaded two drugs on the optical property of the prepared nanoparticles (Fig. 1d). Furthermore, the prepared $\mathrm{CNS}_{\mathrm{D}}$ nanoparticles showed excellent colloidal stability due to their stable hydrodynamic size and PDI over 10 days (Additional file 1: Fig. S1).

\section{Photothermal properties and photothermal-induced drug release performance}

The NIR-II photothermal properties and photothermalinduced release of immune agents from CNS were further investigated. Under conditions of photoirradiation $(1064 \mathrm{~nm})$ at a power intensity of $1 \mathrm{~W} \mathrm{~cm}^{-2}$, the temperatures of $\mathrm{CNS}_{0}, \mathrm{CNS}_{\mathrm{C}}, \mathrm{CNS}_{\text {, }}$, and $\mathrm{CNS}_{\mathrm{D}}$ solution showed an obvious increase up to around $55^{\circ} \mathrm{C}$ in $7 \mathrm{~min}$ (Fig. 1e; 

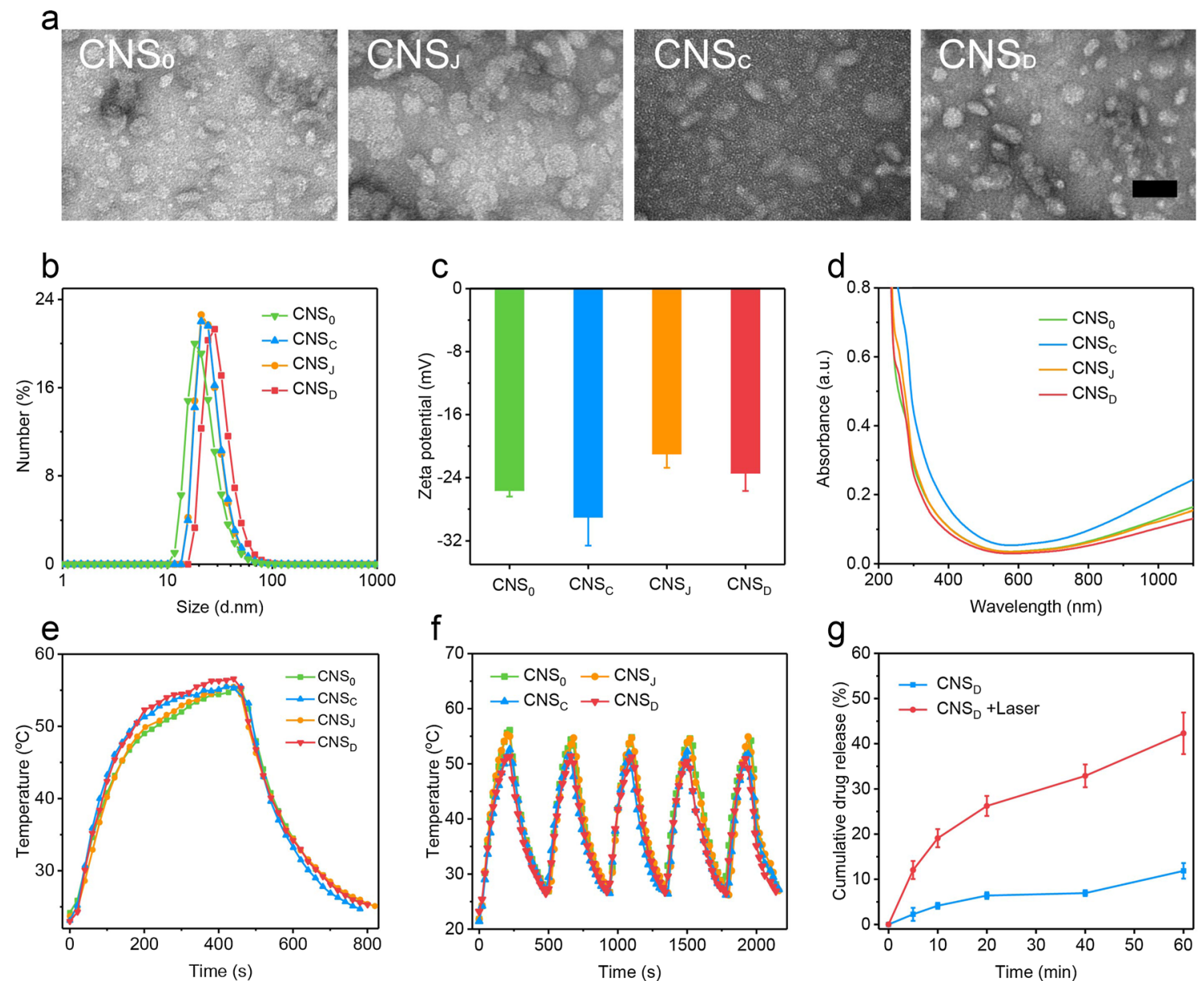

Fig. 1 a Typical TEM images of $C N S_{0}, C N S_{\jmath}, C N S_{C}$ and $C N S_{D}$, the scale bar $=50 \mathrm{~nm}$. b Typical DLS profiles of $C N S_{0}, C N S_{J}, C N S_{C}$, and $C N S_{D}$. $\mathbf{c}$ Zeta potentials of $\mathrm{CNS}_{0}, \mathrm{CNS}_{\mathrm{J}}, \mathrm{CNS}_{\mathrm{C}}$, and $\mathrm{CNS}_{\mathrm{D}}$. $\mathbf{d} \cup \mathrm{UV}$-vis absorption spectra of $\mathrm{CNS}_{0}, \mathrm{CNS}_{\mu}, \mathrm{CNS}_{C}$, and $\mathrm{CNS}_{\mathrm{D}}$. e Photothermal effect of $100 \mu \mathrm{g} / \mathrm{mL} \mathrm{CNS} S_{0}$ $\mathrm{CNS}_{3}, \mathrm{CNS}_{C}$, and $\mathrm{CNS}_{\mathrm{D}}$ with 1064-nm irradiation $\left(1 \mathrm{~W} \mathrm{~cm}{ }^{-2}\right.$ ) followed by laser shut-off. f Photothermal stability assay of $\mathrm{CNS}_{0}, \mathrm{CNS}_{\mathrm{J}}, \mathrm{CNS}_{\mathrm{C}}$, and $\mathrm{CNS}_{\mathrm{D}}$ after five cycles of laser on/off. $\mathbf{g}$ Release of JQ1 from $\mathrm{CNS}_{\mathrm{D}}$ with or without laser irradiation (1064-nm, $1 \mathrm{~W} \mathrm{~cm}^{-2}$ ) for 5 min (the concentrations of CuS and JQ1 for CNS were 100 and $39.5 \mu \mathrm{g} / \mathrm{mL}$, respectively)

Additional file 1: Fig. S2). The photothermal temperature curves exhibited minimal differences after five cycles of heating and natural cooling (Fig. 1f), showing good photothermal stability of the nanoparticles. Furthermore, the photothermal conversion efficiency of $\mathrm{CNS}_{\mathrm{D}}$ was $\approx$ $32.6 \%$, which was similar to that of $\mathrm{CNS}_{0}(32.4 \%), \mathrm{CNS}_{\mathrm{C}}$ (31.8\%), and $\mathrm{CNS}_{\mathrm{J}}$ (31.5\%) (Additional file 1: Fig. S3).

The photo-triggered release properties of the loaded immune agents were further analyzed. Under conditions of photoirradiation $(1064 \mathrm{~nm})$ at a power intensity of $1 \mathrm{~W} \mathrm{~cm}^{-2}$ for $5 \mathrm{~min}$, the cumulative releases of JQ1 and CpG from $\mathrm{CNS}_{\mathrm{D}}$ were $42.3 \%$ and $44.7 \%$ in $1 \mathrm{~h}$, respectively, which were 3.6- and 3.5-fold higher than that without laser irradiation (Fig. 1g; Additional file 1: Fig. S4). The underlying mechanism can be explained as follows: $\mathrm{CNS}_{\mathrm{D}}$ mediated the photothermal effect and induced the dissociation of temperature-responsive liposomes with a phase-transition temperature of around $42{ }^{\circ} \mathrm{C}$, resulting in the on-demand release of drugs.

\section{CNS-mediated intracellular photothermal-activated immune response}

The cellular uptake of CNS was first analyzed in Panc02 cells. The cellular uptake of CNS was confirmed by loading $2.5 \%(\mathrm{w} / \mathrm{w})$ CNS with indocyanine green (ICG), which is a cyanine dye approved by the FDA, to construct four loaded CNS nanoparticles $\left(\mathrm{CNS}_{0} @ \mathrm{ICG}, \mathrm{CNS}_{\mathrm{C}} @\right.$ ICG, CNS $@$ @ICG, and $\mathrm{CNS}_{\mathrm{D}} @ \mathrm{ICG}$ ) (Additional file 1: Fig. S5). The ICG-loaded CNS nanoparticles exhibited identical peaks in the UV-vis absorption spectrum, indicating their successful preparation (Additional file 1: Fig. S6). After a 24-h incubation, the fluorescence intensity of 
$\mathrm{CNS}_{\mathrm{D}}$ cultured in Panc02 cells and 4T1 cells was 105- and 109-fold greater than that of the control group, respectively, suggesting the effective internalization of nanoparticles into cells. There were no obvious differences in fluorescence intensities in both Panc02 cells and 4T1 cells cultured with the four nanoparticles (Fig. 2a, b; Additional file 1: Fig. S7). The cytotoxicity of these CNS nanoparticles was analyzed. The viability of the Panc02 cells was $>90 \%$ after incubation with four CNS nanoparticles for $24 \mathrm{~h}$, indicating the nontoxicity and good biocompatibility of CNS in vitro (Fig. 2c). The capacity for CNS to suppress tumor cells was further assessed. After incubation with $\mathrm{CNS}_{0}, \mathrm{CNS}_{\mathrm{C}}, \mathrm{CNS}_{\text {J }}$, or $\mathrm{CNS}_{\mathrm{D}}$ for $24 \mathrm{~h}$, Panc02 cells were exposed to a $1064 \mathrm{~nm}$ NIR laser at a power density of $1 \mathrm{~W} \mathrm{~cm}^{-2}$ for $5 \mathrm{~min}$. The results showed that cells treated with diverse CNS nanoparticles plus NIRII light all decreased with elevating $\mathrm{CuS}$ concentrations

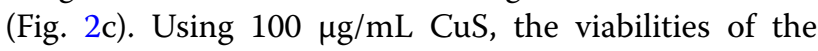

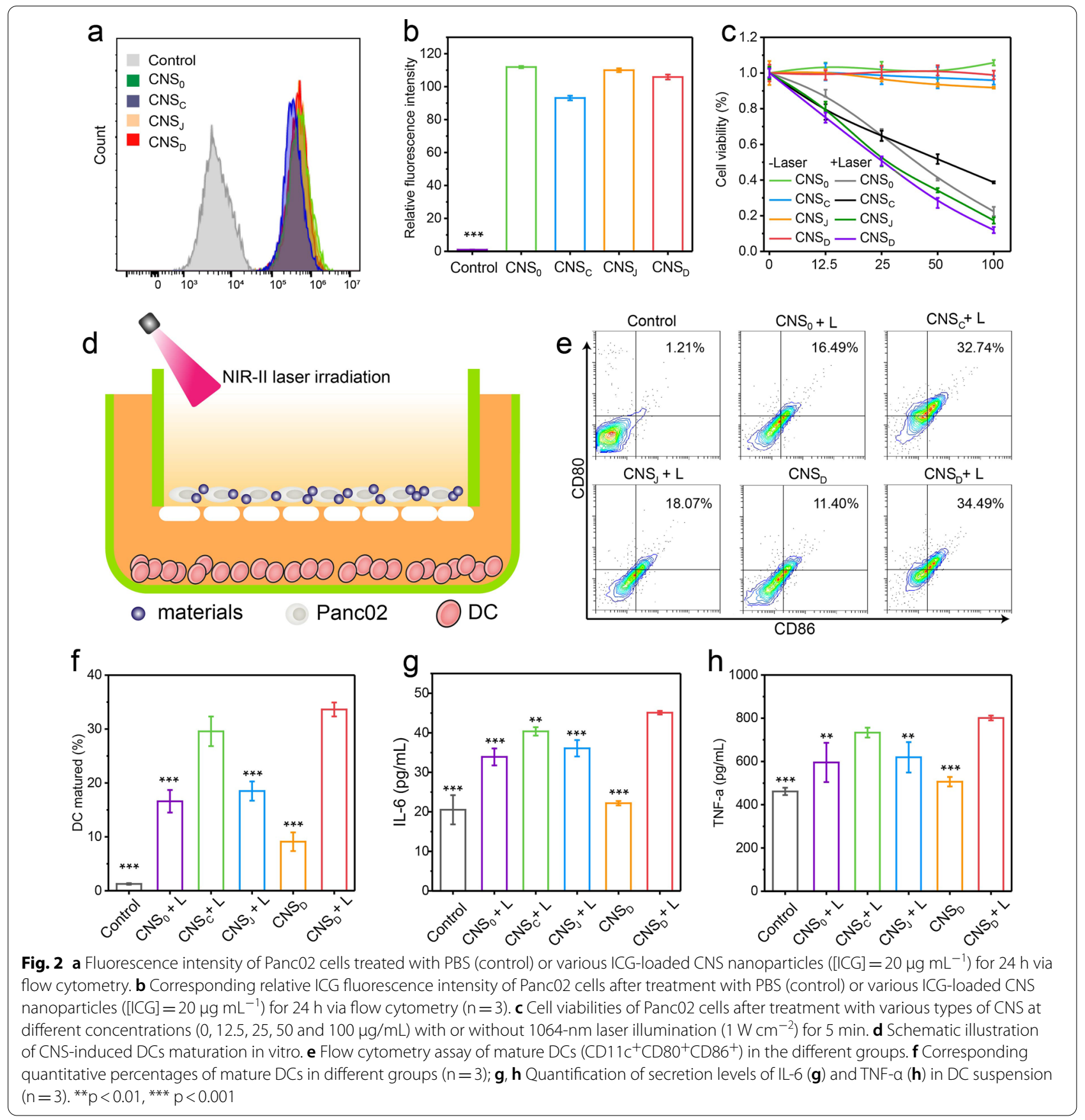


Panc02 cells treated with $\mathrm{CNS}_{0}+\mathrm{L}, \mathrm{CNS}_{\mathrm{C}}+\mathrm{L}, \mathrm{CNS}_{\mathrm{J}}+\mathrm{L}$, and $\mathrm{CNS}_{\mathrm{D}}+\mathrm{L}$ decreased to $24.6 \%, 38.7 \%, 17.3 \%$, and $11.9 \%$, respectively, suggesting excellent CNS-mediated photothermal effects against cell growth.

Exposure of the tumor cells to calreticulin (CRT) as a specific signal for triggering APCs was a characteristic sign of ICD induction. Thus, CRT exposure of the Panc02 cells was further evaluated to validate the performance of CNS-mediated ICD under conditions of NIR-II irradiation in vitro. $24 \mathrm{~h}$ after NIR-II laser irradiation $(1064 \mathrm{~nm}$, $1.0 \mathrm{~W} \mathrm{~cm}{ }^{-2}, 5 \mathrm{~min}$ ), the mean fluorescence intensity (MFI) of CRT in Panc02 cells treated with the four CNS nanoparticles was elevated. Of note, the MFI of CRT in the $\mathrm{CNS}_{\mathrm{D}}+\mathrm{L}$ group was 3.2 and 2.5 -fold higher than that in the control and $\mathrm{CNS}_{\mathrm{D}}$ groups, respectively (Additional file 1: Fig. S8). These data indicate that CNS nanoparticles were capable of efficiently triggering ICD under conditions of NIR-II laser irradiation.

As a key role in human immunity, immature DCs can engulf antigens and transfer them to neighboring lymph nodes, where they are processed into peptides for $\mathrm{T}$ cell activation. Mature DCs can be detected by the co-stimulatory molecules, $\mathrm{CD} 80 / \mathrm{CD} 86$, which are representative markers that signify DC maturation. Murine bone marrow-derived dendritic cells (BMDCs) extracted from C57 mice received different treatments and the corresponding percentages of matured $\mathrm{DCs}\left(\mathrm{CD} 11 \mathrm{c}^{+} \mathrm{CD} 80^{+} \mathrm{CD} 86^{+}\right)$ were then measured by flow cytometry (Fig. 2d). NIR-II laser irradiation significantly elevated the maturation of various CNS-treated DCs compared with the nonlaser irradiation group (Fig. 2e). DC maturation in the $\mathrm{CNS}_{\mathrm{D}}+\mathrm{L}$ group was 26.4-fold higher than in the PBS group. Notably, DC maturation in the $\mathrm{CNS}_{\mathrm{D}}+\mathrm{L}$ group was 3.7, 2.0, and 1.8-fold higher than that of the $\mathrm{CNS}_{\mathrm{D}}$, $\mathrm{CNS}_{0}+\mathrm{L}$, and $\mathrm{CNS}_{\mathrm{J}}+\mathrm{L}$ groups, respectively, suggesting that the NIR-mediated photothermal effect can be attributed to the laser-induced release of tumor antigens and loaded immune-agents (Fig. 2f). However, DC maturation was similar in the $\mathrm{CNS}_{\mathrm{D}}+\mathrm{L}$ and $\mathrm{CNS}_{\mathrm{C}}+\mathrm{L}$ groups, which may be explained by the fact that JQ1 does not directly facilitate DC maturation.

Immune-related cytokines, such as interleukin-6 (IL6) and tumor necrosis factor- $\alpha$ (TNF- $\alpha)$, can be secreted by mature DCs. Thus, we measured the concentration of cytokines in the medium using ELISA kits. The secretion levels of TNF- $\alpha$ and IL- 6 in the NIR-II laser-treated CNS groups were all increased (Fig. $2 \mathrm{~g}, \mathrm{~h}$ ). In particular, levels of IL- 6 and TNF- $\alpha$ in the $\mathrm{CNS}_{\mathrm{D}}+\mathrm{L}$ group were 2.0and 1.6-fold, respectively, higher than that of the $\mathrm{CNS}_{\mathrm{D}}$ group.

\section{CNS-mediated synergistic NIR-II photothermal immunotherapy in Panc02 tumors}

Panc02 tumor-bearing C57BL/6 mice with primary and distant tumors were used to evaluate the curative effect of CNS-mediated NIR-II photothermal immunotherapy in living mice. The mice were intravenously administered with various CNS nanoparticles and the primary tumor was then exposed to NIR-II laser treatment. The growth of primary and distant tumors was subsequently monitored for two weeks (Fig. 3a). The ICG labeled CNS nanoparticles were intravenously injected into the Panc02 tumor-bearing mice to investigate the optimal tumor accumulation of CNS. The fluorescence intensity in tumors of $\mathrm{CNS}_{0}, \mathrm{CNS}_{\mathrm{C}}, \mathrm{CNS}_{\text {}}$, and $\mathrm{CNS}_{\mathrm{D}}$-treated mice gradually increased and peaked at $24 \mathrm{~h}$ post-injection (Additional file 1: Fig. S9a). At this time-point, the intensity of the tumors of CNS-injected mice was at least 5.9fold higher relative to the background, demonstrating the accumulation of nanoparticles into tumors (Additional file 1: Fig. S9b).

The photothermal properties of CNS nanoparticles were further investigated in both Panc02- and 4T1 tumor-bearing mice to examine the effects of PTT in vivo. At $24 \mathrm{~h}$ post-treatment using various CNS nanoparticles, the primary tumors of the mice were exposed to the NIR-II laser $(1064 \mathrm{~nm})$ at a power intensity of $1 \mathrm{~W} \mathrm{~cm}{ }^{-2}$ for $5 \mathrm{~min}$. The temperatures of the region of Panc02 tumors in all CNS-treated groups were gradually elevated and peaked at least $\approx 54.8{ }^{\circ} \mathrm{C}$ for 5 min postirradiation (Fig. 3b, c). Similarly, the temperatures of the region of $4 \mathrm{~T} 1$ tumors in all treated groups were at least $\approx 54.2^{\circ} \mathrm{C}$ for $5 \mathrm{~min}$ post-irradiation (Additional file 1: Fig. S10). These results showed that the CNS nanoparticles have good photothermal properties in vivo. Furthermore, the tumor temperatures in all treated groups were similar at the same time points, showing that all CNS nanoparticles possessed similar photothermal conversion efficacies and intratumoral aggregation.

Due to the good photothermal conversion efficiency and excellent intratumoral aggregation properties of CNS nanoparticles, Panc02 tumor-bearing mice were then randomly divided into six groups to investigate the antitumor capacities of various CNS nanoparticles. After treatment, the curative effects of CNS in vivo were assessed by monitoring the growth of the primary and distant tumors. In the absence of photoirradiation, the growth of primary and distant tumors in $\mathrm{CNS}_{\mathrm{D}}$ and PBStreated mice showed negligible inhibition (Fig. 3d, e). Following photoirradiation, the primary tumor volume in the $\mathrm{CNS}_{\mathrm{D}}$-treated group was effectively suppressed and was 6.7, 4.1, and 3.2-fold lower than $\mathrm{CNS}_{0}, \mathrm{CNS}_{\mathrm{C}}$, and $\mathrm{CNS}_{\Gamma}$-treated mice, respectively. The distant tumor volume in the $\mathrm{CNS}_{\mathrm{D}}$-treated group was also effectively 


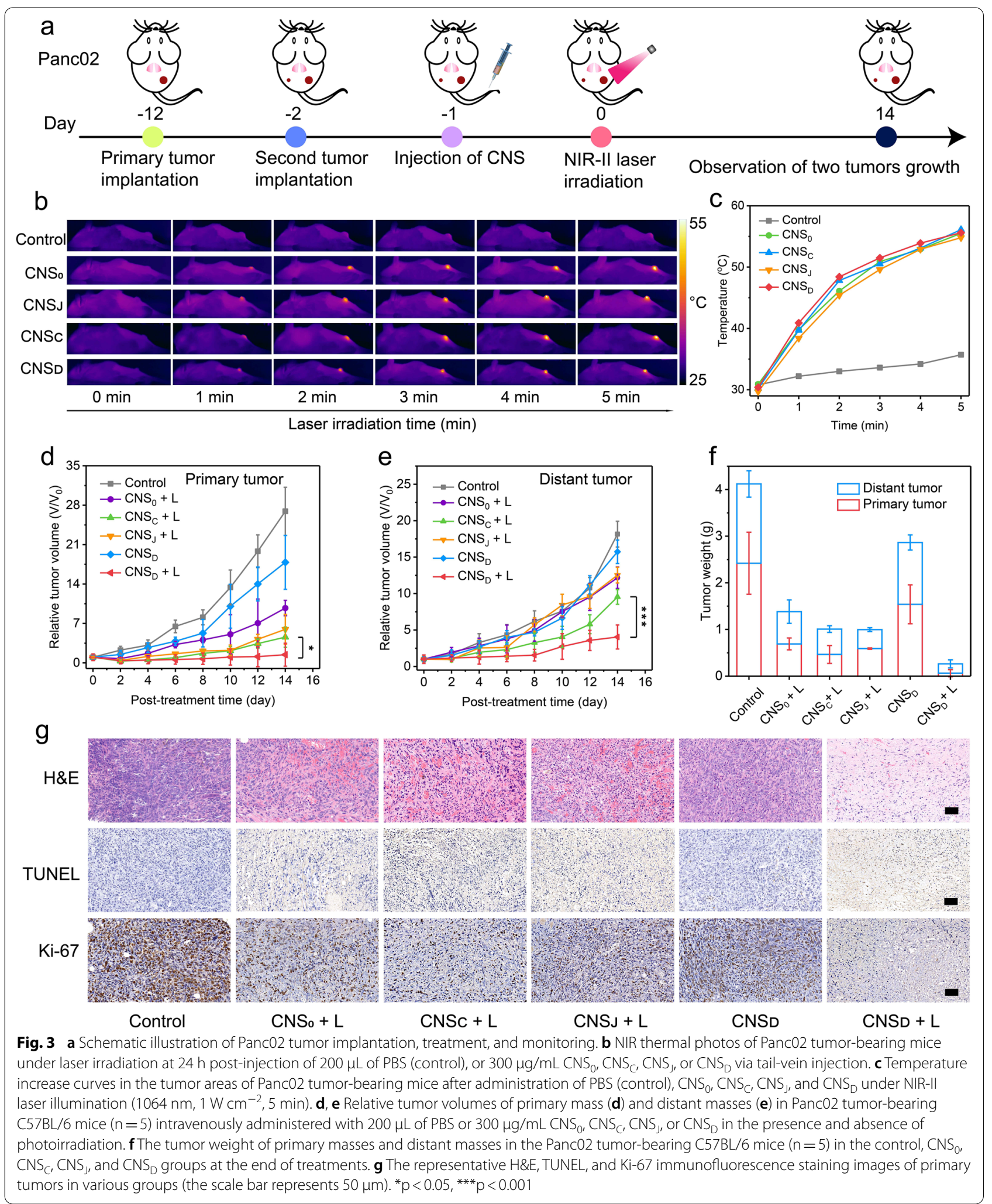


inhibited and was 3.0, 2.4, and 3.1-fold lower than $\mathrm{CNS}_{0}$, $\mathrm{CNS}_{\mathrm{C}}$, and $\mathrm{CNS}_{\text {T }}$-treated mice, respectively. Furthermore, the tumor weights of the primary and distant tumors in the $\mathrm{CNS}_{\mathrm{D}}+\mathrm{L}$ group were 0.06 and $0.2 \mathrm{~g}$, which was 25.7 and 6.6-fold lower than that in the $\mathrm{CNS}_{\mathrm{D}}$ group, respectively (Fig. 3f). The pathological data from the $\mathrm{CNS}_{\mathrm{D}}+\mathrm{L}$ group exhibited larger regions of cell apoptosis and necrosis [hematoxylin and eosin (H\&E) and terminal deoxynucleotidyl transferase dUTP nick end labeling (TUNEL)] in the primary tumors compared with the $\mathrm{CNS}_{0}+\mathrm{L}, \mathrm{CNS}_{\mathrm{C}}+\mathrm{L}$, and $\mathrm{CNS}_{\mathrm{J}}+\mathrm{L}$ groups (Fig. 3g). The PBS and $\mathrm{CNS}_{\mathrm{D}}$ groups showed no obvious areas of apoptosis in these masses. Similarly, Ki-67 staining images showed the greatest inhibition of cancer cell proliferation in the $\mathrm{CNS}_{\mathrm{D}}+\mathrm{L}$ group.

\section{CNS-mediated synergistic NIR-II photothermal immunotherapy on 4T1 tumors}

4T1 tumor-bearing Balb/c mice with primary and distant tumors were given various treatments and monitored to investigate the efficacy of CNS nanoparticles-mediated photothermal immunotherapy in inhibiting lung metastasis (Fig. 4a). The inhibition effects of both primary and distant tumors were investigated due to the desirable photothermal effects of CNS nanoparticles in 4T1 tumor-bearing mice. In contrast to the results of the Panc02 tumor-bearing mouse model, the growth of primary and distant tumors was not suppressed in the control and $\mathrm{CNS}_{\mathrm{D}}$ groups. However, photoirradiation showed the greatest suppressive effects of both primary and distant tumors in $\mathrm{CNS}_{\mathrm{D}}$-treated mice compared with $\mathrm{CNS}_{0}, \mathrm{CNS}_{\mathrm{C}}$, and $\mathrm{CNS}_{\mathrm{I}}$-treated mice (Fig. 4b, c). Compared with the other groups, the $\mathrm{CNS}_{\mathrm{D}}+\mathrm{L}$ group exhibited the most apoptosis of tumor cells, as demonstrated by the H\&E staining of the tumor biopsy (Fig. 4e). The lungs of the 4T1 tumor-bearing mice were extracted and pathologically examined 30 days after various treatments to investigate the therapeutic effects of CNS-mediated inhibition of lung metastasis (Fig. 4d, f). The greatest inhibitory effect of tumor lung metastasis was observed in $\mathrm{CNS}_{\mathrm{D}}$-treated mice. Furthermore, the average number of pulmonary metastasis in the $\mathrm{CNS}_{\mathrm{D}}+\mathrm{L}$ group was at least six times lower than that in the other groups. These data showed that $\mathrm{CNS}_{\mathrm{D}}$ nanoparticles possessed the potential to inhibit diverse malignant tumors and prevent tumor metastasis.

\section{CNS-mediated synergistic immune response in vivo}

The mechanisms of CNS-mediated photothermal immune response in vivo were further evaluated due to the superior suppression of primary tumors and metastatic tumors.
An in-depth analysis of the key processes of the immune response in vivo, including ICD induction, DC maturation, and $\mathrm{T}$ cell infiltration, was performed to investigate the CNS-based photothermal immune-activation and the synergic effects. Since the induction of ICD is the first step in photothermal immune activation, activation of ICD triggered by CNS nanoparticles under laser irradiation was analyzed first. The representative biomarkers of ICD including adenosine triphosphate (ATP), CRT, and expression of high mobility group box 1 protein (HMGB1) were used to facilitate the uptake, processing, and presentation of tumor antigens in DCs. One day after treatment, the intratumoral ATP levels of various CNS nanoparticles plus laser irradiation were elevated and compared with the single PBS-treated and $\mathrm{CNS}_{\mathrm{D}}$-treated groups. The ATP levels of the $\mathrm{CNS}_{\mathrm{D}}+\mathrm{L}$ group were 2.2 and 1.8-fold higher than those of the control and $\mathrm{CNS}_{\mathrm{D}}$ groups, respectively (Fig. 5a). Moreover, there was a negligible difference in intratumoral ATP levels between the four CNS nanoparticles with photoirradiation, showing that ATP was mainly influenced by NIR-irradiated CNS nanoparticles. Immunohistochemical staining of the tumor section revealed CRT in the tumors as a brown signal. Almost no obvious brown signal was shown in the tumors after treatment with $\mathrm{CNS}_{\mathrm{D}}$ alone or PBS (Fig. 5b). In contrast, tumors treated with various CNS nanoparticles with photoirradiation exhibited an obvious enhanced brown signal. HMGB1 was shown as a red fluorescent signal in the immunofluorescence staining images. Similarly, compared with the $\mathrm{CNS}_{\mathrm{D}}$ alone and PBS-treated groups, tumors treated with diverse CNS nanoparticles with photoirradiation exhibited significantly enhanced red fluorescence signals (Fig. 5c). These data suggested that CNS-mediated NIR-II PTT was able to induce intratumoral ICD.

The tumor-draining lymph nodes in C57BL/6 mice were collected after treatment and measured using flow cytometry to evaluate DC maturation $\left(\mathrm{CD} 11 \mathrm{c}^{+} \mathrm{CD} 80^{+} \mathrm{CD} 86^{+}\right)$(Additional file 1: Fig. S11). The percentage of matured DCs in $\mathrm{CNS}_{\mathrm{D}}$-treated mice with laser irradiation was the highest, and was 2.4, 2.1, and 1.6-fold higher than that in the control, $\mathrm{CNS}_{\mathrm{D}}$, and $\mathrm{CNS}_{\mathrm{J}}+\mathrm{L}$ groups, respectively, suggesting that CNSmediated hyperthermia could activate DCs maturation via the synergic action of PTT-induced ICD and the photothermal-induced release of immune-agents (Fig. 5d, e). As for PD-L1 expression, the inhibitory effect of JQ1 on PD-L1 was firstly be verified in vitro. The western-blot analysis showed that the free or released JQ1 was able to effectively downregulate the IFN- $\gamma$-stimulated PD-L1 expression (Additional file 1: Fig. S12). Then, since JQ1 facilitates the downregulation of PD-L1 expression, we examined whether NIR-II 


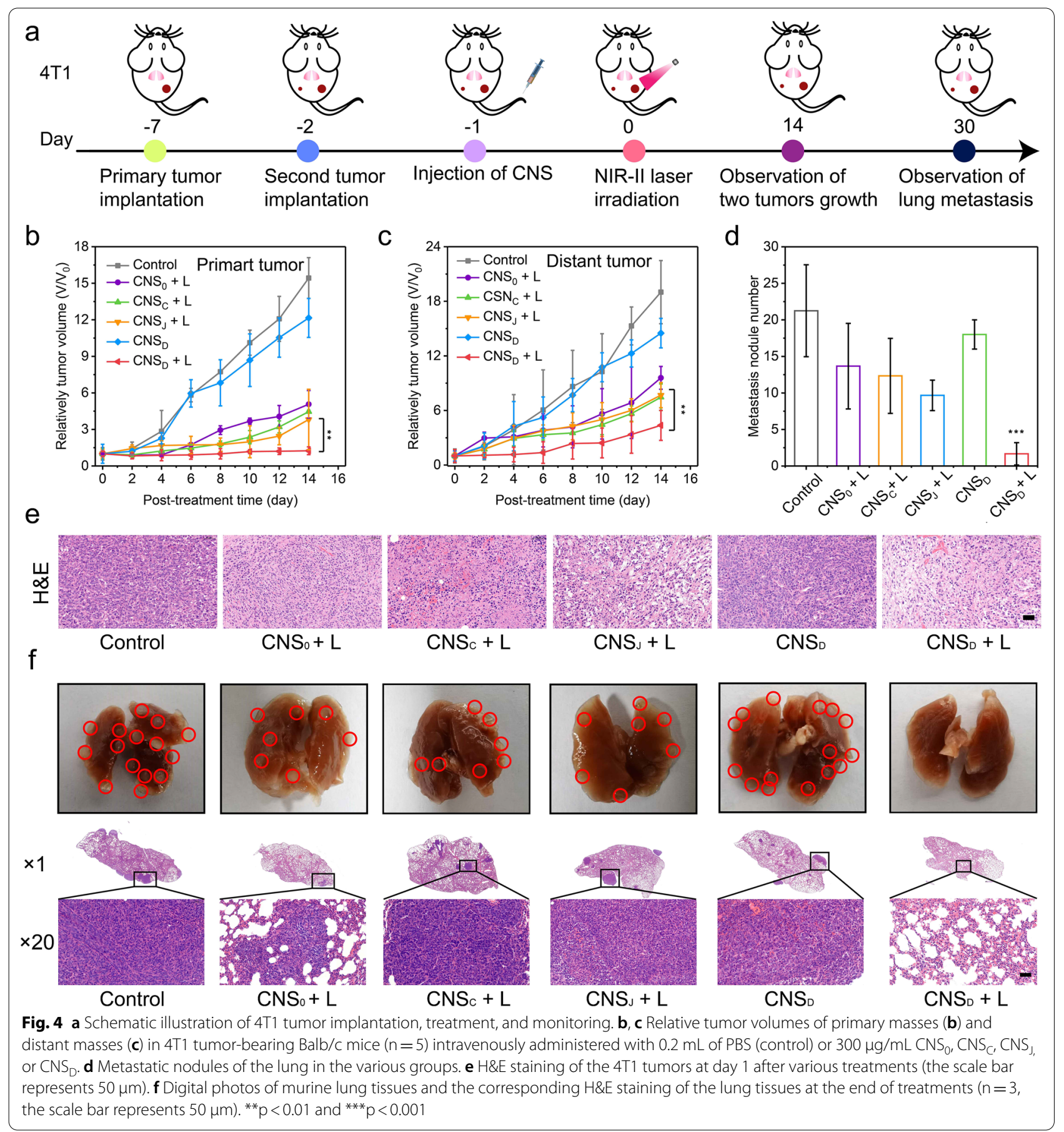

laser-induced JQ1 released from $\mathrm{CNS}_{\mathrm{D}}$ could suppress PD-L1 expression in Panc02 tumor xenografts in vivo by examining immunohistochemical staining of the tumor section. As shown in the representative immunohistochemistry staining images, the brown signal intensity in the $\mathrm{CNS}_{\mathrm{D}}+\mathrm{L}$ and $\mathrm{CDS}_{\mathrm{J}}+\mathrm{L}$ groups was significantly weakened compared with those in the other treatment groups (Fig. 5f). The brown signal intensity in the $\mathrm{CNS}_{\mathrm{D}}$ group without photoirradiation did not decrease compared with that in the $\mathrm{CNS}_{\mathrm{D}}$ group with photoirradiation, implying that tumor PD-L1 expression decreased due to NIR laser-induced JQ1 release from $\mathrm{CNS}_{\mathrm{D}}$ nanoparticles.

Cytotoxic $\mathrm{T}$ lymphocytes, such as $\mathrm{CD} 8^{+} \mathrm{T}$ cells, can identify and kill tumor cells [49]. Hence, tumor tissues were collected after various treatments to assess 
the percentage of cytotoxic $\mathrm{T}$ lymphocytes cells $\left(\mathrm{CD}^{+} /\right.$ $\mathrm{CD}^{+}$) via flow cytometric analysis to investigate the CNS-mediated synergized antitumor immune response (Additional file 1: Fig. S13). Levels of $\mathrm{CD}^{+} \mathrm{T}$ cells in various CNS nanoparticles-treated mice were all increased after photoirradiation compared with those without photoirradiation. In particular, the percentages of $\mathrm{T}$ cells $\left(\mathrm{CD}^{+} / \mathrm{CD}^{+}\right)$in the $\mathrm{CNS}_{\mathrm{D}}+\mathrm{L}$ group were 1.6, 1.2, and 1.2-fold higher than those in the $\mathrm{CNS}_{0}+\mathrm{L}, \mathrm{CNS}_{\mathrm{C}}+\mathrm{L}$, and $\mathrm{CNS}_{\mathrm{J}}+\mathrm{L}$ groups, respectively (Fig. $5 \mathrm{~g}$, h). Similarly, immunofluorescence analysis revealed a greater red fluorescence intensity in the $\mathrm{CNS}_{\mathrm{D}}+\mathrm{L}$ group for CD8 than that in other groups, which is in keeping with the flow cytometry results (Fig. 5i). These results indicated that $\mathrm{CNS}_{\mathrm{D}}$-mediated photothermal immunotherapy enabled the acquisition of synergetic antitumor immune response by combining the photothermally released immunoregulators and photothermal-induced immune response. Furthermore, the secretion of cytokines, such as IL-6, TNF- $\alpha$, and interferon-gamma (IFN- $\gamma$ ), is a key indicator of an antitumor immune response [21]. Therefore, the levels of these cytokines in the serum of Panc02 tumorbearing C57BL/6 mice were also investigated by ELISA. The levels of IL- 6 , TNF- $\alpha$, and IFN- $\gamma$ in the $\mathrm{CNS}_{\mathrm{D}}+\mathrm{L}$ group were the highest and were 1.3, 1.2, and 1.2-fold higher than those in other groups (Fig. $5 \mathbf{j}-1$ ).

\section{Gene expression analysis in vivo}

Transcriptomics analysis of $\mathrm{CNS}_{\mathrm{D}}$ and PBS-treated mice was conducted to thoroughly investigate the mechanisms of immune activation at the genetic level in vivo. Analysis of immune-related genes across the whole genome revealed a total of 75 differentially expressed immunerelated genes, among which, 57 were upregulated and 18 were downregulated (Additional file 1: Fig. S14). These differentially expressed immune-related genes were depicted in the heat map (Fig. 6a). Among the upregulated immune-related expressed genes, gene ontology (GO) process analyses and Kyoto Encyclopedia of Genes and Genomes (KEGG) pathway analyses were further performed to determine biological information, such as regulation pathway and biomolecular function. GO process analyses showed that the most enriched pathways included immune response, immune system response, cytokine-mediated signaling pathway, and regulation of immune response, which are closely related to immune activation (Fig. 6b). KEGG pathway analyses also indicated that several immune activation-related pathways, including Toll-like receptor signaling pathway and IL-17 signaling pathway, were enriched in $\mathrm{CNS}_{\mathrm{D}}$-treated mice (Fig. 6c). In the $\mathrm{CNS}_{\mathrm{D}}$-treated groups, several upregulated genes, including Tnf, Irf7, Jun, Ccl3, and Ccl4, were associated with the Toll-like receptor signaling pathway, which plays a major role in proinflammatory cytokineinduced DC maturation, implying that combined $\mathrm{CNS}_{\mathrm{D}}$ and laser irradiation treatment may reawaken the antitumor immune response in the immunosuppressive tumor microenvironment $[50,51]$.

\section{Biocompatibility of CNS nanoparticles in vivo}

The biocompatibility and biotoxicity of CNS nanoparticles were evaluated in vivo. No obvious behavioral abnormalities or weight loss were observed during the treatment of both 4T1 tumor-bearing Balb/c mice and Panc02 tumor-bearing mice (Additional file 1: Figs. S15, 16). Moreover, after treatment, $H \& E$ staining images showed that regions with necrosis or apoptosis were rarely detected in the murine major organs, including heart, liver, spleen, lung, and kidney in the different treatment groups (Additional file 1: Figs. S17, 18). Additionally, analysis of long-term biotoxicity in C57BL/6 mice revealed no significant differences in diversely vital blood parameters, and liver and kidney function indexes among the Control, D15, and D30 groups (Additional file 1: Fig. S19). The corresponding histological morphology in the $H \& E$ staining images remained normal at different treatment points (Control, D15, and D30). These results indicated the perfect biocompatibility of CNS nanoparticles for tumor immunotherapy in vivo.

\footnotetext{
(See figure on next page.)

Fig. 5 NIR-II photoactivated immune activation in vivo. a Intratumoral levels of ATP in Panc02tumor-bearing C57BL/6 mice in the different groups after intravenous injection of $200 \mu \mathrm{L}$ of PBS or $300 \mu \mathrm{g} \mathrm{mL}^{-1} \mathrm{CNS}_{0}, \mathrm{CNS}_{C}, \mathrm{CNS}_{\text {, }}$ or $\mathrm{CNS}_{\mathrm{D}}$. $\mathbf{b}$ Immunohistochemical staining photos of CRT in tumors sections with different treatments at day 1 post-treatment (blue signal represents cell nuclei and brown signal represents CRT; the scale bar represents $100 \mu \mathrm{m}$ ). c Immunofluorescence staining photos of HMGB1 in tumor sections with different treatments at day 1 post-treatment (blue signal represents cell nuclei and brown signal represents HMGB1; the scale bar represents $50 \mu \mathrm{m}$ ). d, e Flow cytometric plots (d) and corresponding quantitative percentages (e) of matured DCs $\left(C D 80^{+} \mathrm{CD} 86^{+}\right.$gated on $\left.\mathrm{CD} 11 \mathrm{C}^{+}\right)$in tumor-draining lymph nodes of Panc02 tumor-bearing $\mathrm{C} 57 \mathrm{BL} / 6$ mice in various groups at day 3 post-treatment. $\mathbf{f}$ Immunohistochemical staining photos of PD-L1 in tumors sections with different treatments at day 14 post-treatment (blue signal represents cell nuclei and brown signal represents PD-L1; the scale bar represents $100 \mu \mathrm{m}) . \mathbf{g}, \mathbf{h}$ Flow cytometric plots $(\mathbf{g})$ and corresponding quantitative percentages $(\mathbf{h})$ of $\mathrm{CD}^{+} / \mathrm{CD} 4^{+} \mathrm{T}$ cells and $\mathrm{CD} 3^{+} / \mathrm{CD}^{+} \mathrm{T}$ cells in distant tumors of Panc02 tumor-bearing C57BL/6 mice in various groups at day 10 post-treatment. $\mathbf{i}$ Immunofluorescence staining of CD8 in tumors sections with different treatments at day10 post-treatment (blue signal represents cell nuclei and brown signal represents HMGB1; the scale bar represents $50 \mu \mathrm{m}$ ). $\mathbf{j}$-I Serum levels of cytokines including IL-6 (j), TNF- $a(\mathbf{k})$, and IFN- $\gamma(\mathbf{I})$ in Panc02 tumor-bearing C57BL/6 mice in various groups at day 3 post-treatment. ${ }^{*} \mathrm{p}<0.05$, ${ }^{* *} p<0.01$, and ${ }^{* * *} p<0.001$
} 


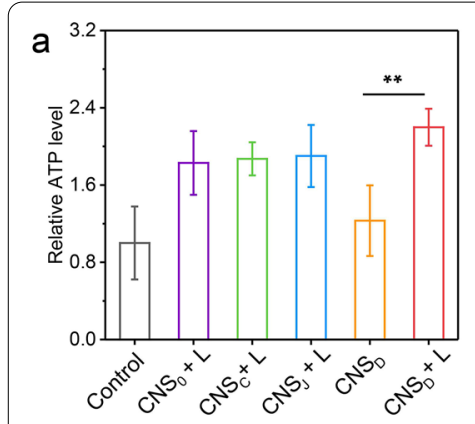

d

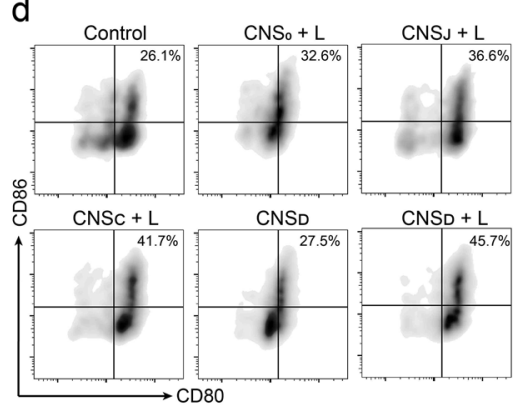

g

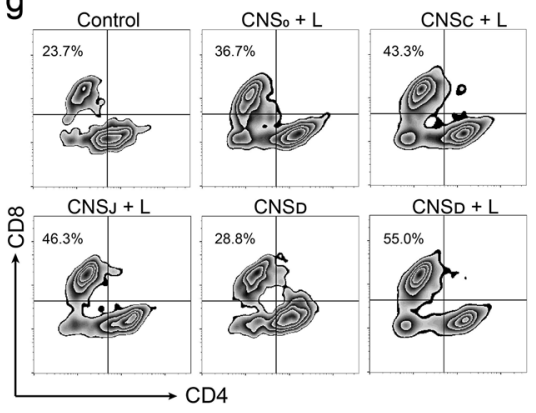

j

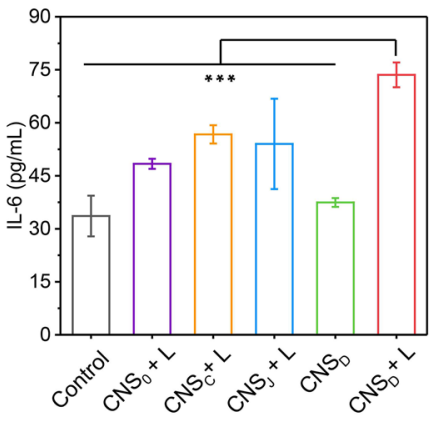

b

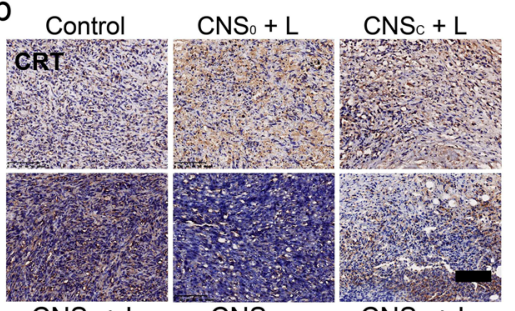

$\mathrm{CNS}_{\jmath}+\mathrm{L}$ e

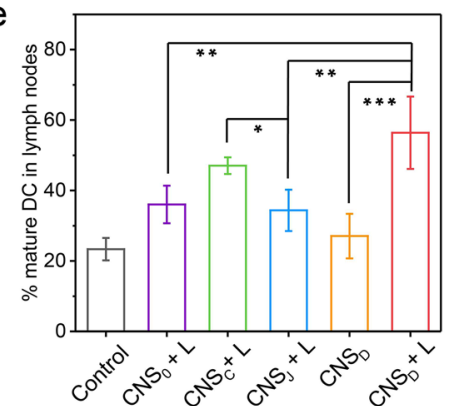

h

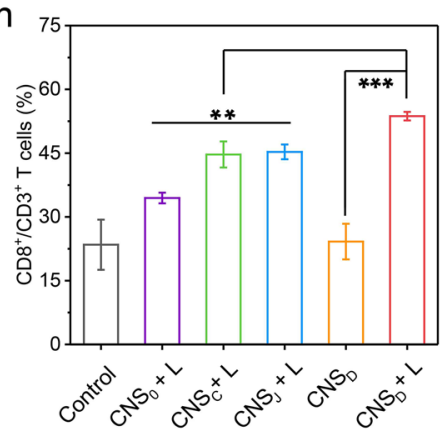

k

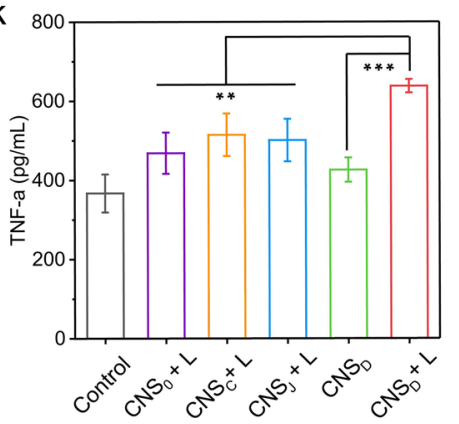

C

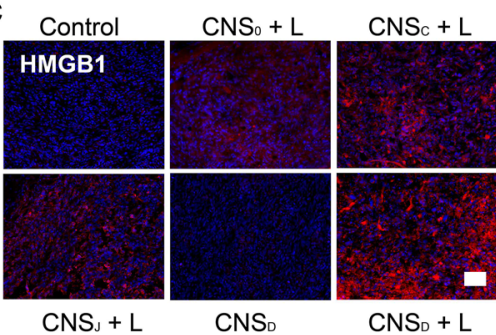

f

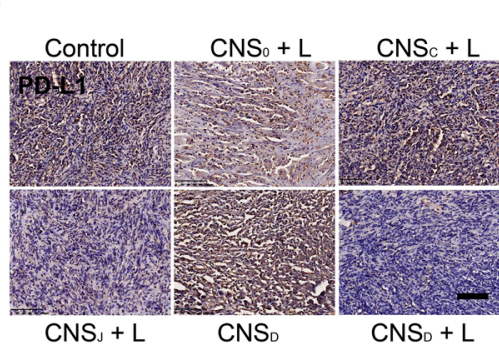

i

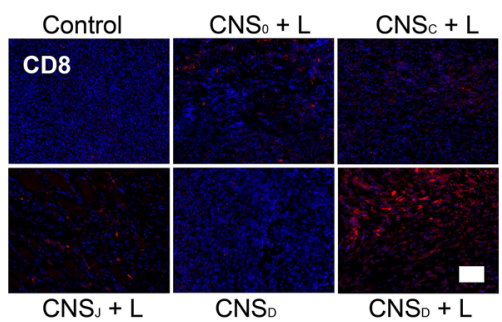

I

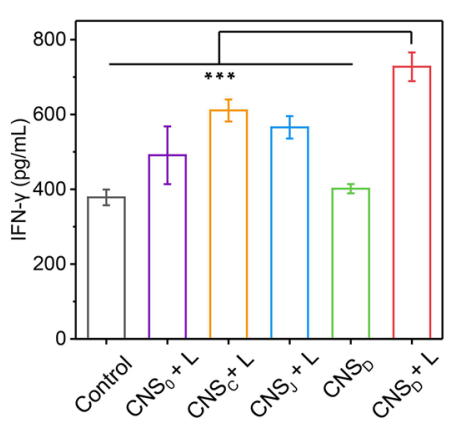

Fig. 5 (See legend on previous page.)

\section{Conclusion}

In conclusion, in the present study, a spatiotemporally controllable CNS nanoparticle was developed to achieve NIR-II photothermal-synergized immunotherapy via remotely photoactivated release of immune agents in specific areas. The $\mathrm{CNS}_{\mathrm{D}}$ nanoparticles possessed a satisfactory photothermal conversion efficiency $(\approx$ $32.6 \%)$ and enabled the effective accumulation in the murine tumor tissues after systemic administration. Under conditions of NIR-II photoirradiation, $\mathrm{CNS}_{\mathrm{D}}$ rapidly elevated the localized temperature, leading to tumor ablation and induction of ICD, and precisely melted the 


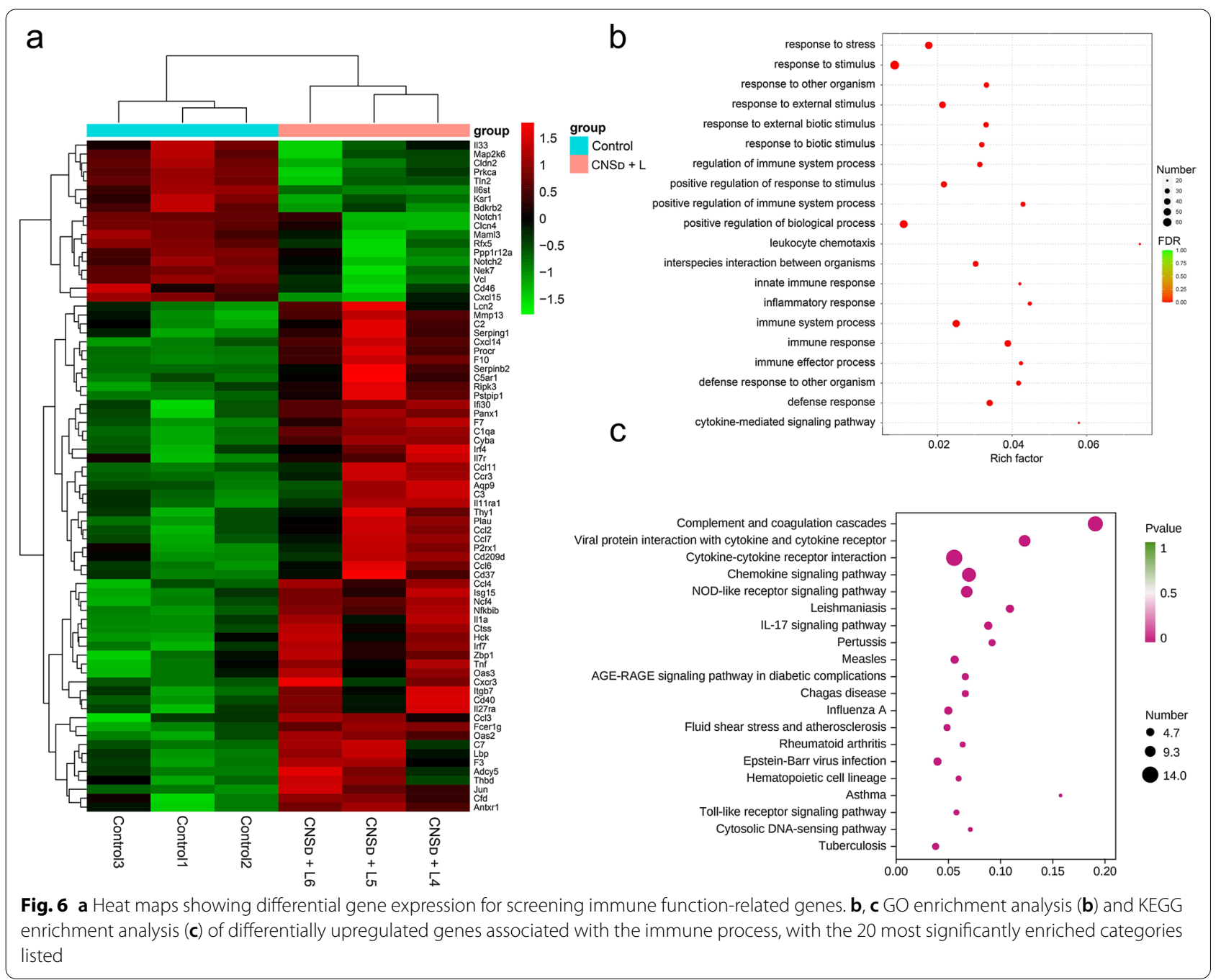

protective lipid layer to release two antitumor immune agents in the tumor region. Levels of matured DCs and $\mathrm{CD}^{+} \mathrm{T}$ cells in $\mathrm{CNS}_{\mathrm{D}}$-treated mice were increased by 2.4 and 2.3-fold, respectively, compared with those in the control group. Therefore, prepared CNS nanoparticlesmediated photothermal-synergized immunotherapy radically suppressed tumor growth in two types of murine models and also effectively inhibit pulmonary metastasis, suggesting a potentially novel strategy for safe and efficient photoactivated immunotherapy.

\section{Abbreviations}

NIR-II: Second near-infrared; CuS: Copper sulfide; TLR-9: Toll-like receptor-9; PD-L1: Programmed death-ligand 1; ICD: Immunogenic cell death; ICBs: Immune checkpoint inhibitors; PD-1: Programmed death 1; PD-L1: Programmed death ligand 1; CTLA-4: Cytotoxic T lymphocyte-associated protein 4; FDA: Food and Drug Administration; PTT: Photothermal therapy; DAMPs: Damage-associated molecular patterns; DCs: Dendritic cells; MPE: Maximum permissible exposure; TLR-9: Toll-like receptor-9; DPPC: 1,2-Dipalmitoyl-sn-glycerol-3-phosphocholine; DSPE-PEG 2 :
1,2-Distearoyl-sn-glycero-3-phosphoethanolamine-poly(ethylene glycol)2000; APCs: Antigen-presenting cells; ANOVA: One-way analysis of variance; EE: Encapsulation efficiency; LC: Loading capacity; TEM: Transmission electron microscopy; DLS: Dynamic light scattering; PBS: Phosphate-buffered saline; UV-vis: Ultraviolet-visible; ICG: Indocyanine green; CRT: Calreticulin; MFI: Mean fluorescence intensity; BMDCs: Bone marrow-derived dendritic cells; IL-6: Interleukin-6; TNF-a: Tumor necrosis factor-a; H\&E: Hematoxylin and eosin; TUNEL: Terminal deoxynucleotidyl transferase dUTP nick end labeling; ATP: Adenosine triphosphate; HMGB1: High mobility group box 1 protein; IFN- $\gamma$ : Interferon-gamma; GO: Gene ontology; KEGG: Kyoto Encyclopedia of Genes and Genomes

\section{Supplementary Information}

The online version contains supplementary material available at https://doi. org/10.1186/s12951-021-01197-5.

Additional file 1: Fig. S1. Hydrodynamic diameters and PDI of CNS after storage in $1 \times$ PBS buffer $(\mathrm{pH}=7.4)$ during 10 days $(n=3)$. Fig. S2. NIR images of $\mathrm{CNS}_{0}, \mathrm{CNS}_{\mathrm{C}}, \mathrm{CNS}_{\text {, }}$ and $\mathrm{CNS}_{\mathrm{D}}\left([\mathrm{CuS}]=100 \mu \mathrm{g} \mathrm{mL}^{-1}\right.$ ) under the NIR-II laser irradiation (1064 $\mathrm{nm}, 1.0 \mathrm{~W} \mathrm{~cm}^{-2}$ ) for $5 \mathrm{~min}$. Fig. S3. The time constant for heat transfer from the system is determined by applying the linear time data from the cooling period of (a) versus the negative natural logarithm of driving force temperature. Fig. S4. Release of CpG 
from $\mathrm{CNS}_{\mathrm{D}}$ with or without laser irradiation $\left(1064-\mathrm{nm}, 1 \mathrm{~W} \mathrm{~cm}{ }^{-2}\right.$ ) for $5 \mathrm{~min}$ (the concentrations of CuS and CpG for CNS were 100 and $2.3 \mu \mathrm{g} / \mathrm{mL}$, respectively). Fig. S5. Schematic illustration of the synthesis of ICG-loaded CNS nanoparticles (CNS,@ICG, CNS @@ICG, CNS,@ICG, CNS @@ICG) for tracing the nanoparticle trajectory. Fig. S6. UV-vis absorption spectrums ofCNS @|CG, CNS @ @ICG, CNS,@|CG, and CNS $@$ @ICG. Fig. S7. Fluorescence intensity of $4 \mathrm{~T} 1$ cells treated with PBS (control) or various ICG-loaded CNS nanoparticles ([ICG] $=20 \mathrm{\mu g} \mathrm{mL}^{-1}$ ) for $24 \mathrm{~h}$ via flow cytometry. Fig. S8. Relative mean fluorescence intensity (MFI) of CRT in Panc02 cells after different treatments. Fig. S9. The NIR fluorescence imaging of xenograft Panc02tumor-bearing C57BL/6 living mice at 0, 8, 24, and $36 \mathrm{~h}$ after systemic administration of CNS@|CG through tail-vein administration $(0.2$ $\mathrm{mL},[\mathrm{ICG}]=2 \mathrm{mg} \mathrm{kg}^{-1}$. The fluorescence images were collected with excitation at $710 \mathrm{~nm}$ and emission at $790 \mathrm{~nm}$, and the tumors were marked by white circles. (b) The fluorescence intensity of tumor regions of mice at different post-injection times of $(n=3)$. Fig. S10. (a) NIR thermal photos of $4 \mathrm{~T} 1$ tumor-bearing mice under laser irradiation at $24 \mathrm{~h}$ post-injection of PBS, $\mathrm{CNS}_{0}, \mathrm{CNS}_{C}, \mathrm{CNS}_{\text {, }}$ and $\mathrm{CNS}_{\mathrm{D}}$ through tail-vein injection $(0.2 \mathrm{~mL}$, the concentration of $\mathrm{CuS}=300 \mathrm{\mu g} / \mathrm{mL}$ for $\mathrm{CNS}_{0}, \mathrm{CNS}_{C}, \mathrm{CNS}_{\text {J }}$, and $\mathrm{CNS}_{\mathrm{D}}$ ); (b) Temperature elevation curves of tumors in $4 \mathrm{~T} 1$ tumor-bearing mice after administration of Control (PBS), $\mathrm{CNS}_{0}, \mathrm{CNS}_{\mathrm{C}}, \mathrm{CNS}_{\text {, }}$ and $\mathrm{CNS}_{\mathrm{D}}$ under NIR-II laser illumination (1064 nm, 1W cm${ }^{-2}, 5 \mathrm{~min}$ ). Fig. S11. Gating strategies for flow cytometry assay of matured $\mathrm{CD} 80^{+} \mathrm{CD} 86^{+} \mathrm{DC}$ in tumor-draining lymph nodes of Panc02 tumor-bearing C57BL/6 mice. Fig. S12. Westernblot analysis of JQ1-induced downregulation of PD-L1 in Panc02 cells ( $200 \mathrm{nM}$ of JQ1 and $100 \mathrm{ng} / \mathrm{ml}$ of IFN-ץ). Fig. S13. Gating strategy for flow cytometry assay of $\mathrm{CD} 4^{+} \mathrm{T}$ cells and $\mathrm{CD} 8^{+} \mathrm{T}$ cells in distant tumors of Panc02 tumor-bearing C57BL/6 mice. Fig. S14. A volcano plot showing the up-regulated or insignificantly expressed or down-regulated genes when comparing the $\mathrm{CNS}_{\mathrm{D}}$-treated group with the Control (PBS) group. Fig. S15. Body weights of Panc02 tumor-bearing C57BL/6 mice in different groups within 14 days of treatment (Control (PBS), $\mathrm{CNS}_{0}, \mathrm{CNS}_{\mathrm{C}^{\prime}} \mathrm{CNS}$, and $\mathrm{CNS}_{\mathrm{D}}, 0.2 \mathrm{~mL}$, [CuS] $=300 \mu \mathrm{g} / \mathrm{mL}, \mathrm{n}=5$ ). Fig. S16. Body weights of $4 \mathrm{~T} 1$ tumor-bearing Balb/c mice in different groups within 14 days of treatment (Control (PBS), $\mathrm{CNS}_{0}, \mathrm{CNS}_{\mathrm{C}}, \mathrm{CNS}_{\text {, }}$ and $\mathrm{CNS}_{\mathrm{D}}, 0.2 \mathrm{~mL}$, [CuS] $=300$ $\mu \mathrm{g} / \mathrm{mL}, \mathrm{n}=5$ ). Fig. S17. Representative histological H\&E staining images of major organs (heart, liver, spleen, lung, and kidney) were collected from Panc02 tumor-bearing C57BL/6 mice in different treatment groups at the end of treatment (Control (PBS), $\mathrm{CNS}_{0}, \mathrm{CNS}_{\mathrm{C}}, \mathrm{CNS}$, and $\mathrm{CNS}_{\mathrm{D}}, 0.2 \mathrm{~mL}$, [CuS] $=300 \mu \mathrm{g} / \mathrm{mL}$ ). The scale bar represents $50 \mu \mathrm{m}$. Fig. S18. Representative histological H\&E staining photos of major organs (heart, liver, spleen, lung, and kidney) in healthy C57BL/6 mice before treatment (Control) and after tail-intravenous injection of CNS $(0.2 \mathrm{~mL}$, [CuS] $=00 \mu \mathrm{g} / \mathrm{mL}$ ) for 15 (Day 15) and 30 days (Day 30). The scale bar represents $50 \mu \mathrm{m}$. Fig. S19. The levels of (a) alanine aminotransferase (ALT), (b) aspartate aminotransferase (AST), (c) y-glutamyl transpeptidase (GGT), (d) urea, (e) creatinine (CREA), (f) red blood cells (RBC), (g) hemoglobin (HGB), (h) mean corpuscular hemoglobin $(\mathrm{MCH})$, (i) hemoglobin concentration $(\mathrm{MCHC})$, (j) red cell distribution width (RDW-SD), (k) red cell volume distribution width (RDW-CV), (I) platelet (PLT), (m) plateletcrit (PCT), (n) mean platelet volume (MPV), and (o) platelet distribution width (PDW) in the blood of healthy C57BL/6 mice before treatment (D0) and after tail-intravenous administration of $\mathrm{CNS}_{\mathrm{D}}(0.2 \mathrm{~mL},[\mathrm{CuS}]=300 \mu \mathrm{g} / \mathrm{mL})$ for 15 (D15), and 30 days (D30) $(\mathrm{n}=3)$.

\section{Acknowledgements}

We appreciate Prof. Mengsu Zeng (Department of Radiology, Zhongshan Hospital, Fudan University) for the administrative and funding assistance in the experiment.

\section{Authors' contributions}

SHT and YTZ participated in all experiments and data analysis. SHT and LX contributed to manuscript preparation and writing. LX, LYY, LJK, LY, and PPK contributed to data curation and data analysis. PPK, LY, and WXH contributed to cell experiments and animal experiments. NDL, PPK, LY,WXH, WXL contributed to project design, and supervision; $S H T, L Y$, and $W X L$ contributed to funding acquisition. $L X, N D L, L Y, W X L, W X H$, and PPK contributed to the manuscript review. All authors read and approved the final manuscript.

\section{Funding}

This work was supported by the Shanghai Municipal Key Clinical Specialty (shslczdzk03202) and the Opening Project of State Key Laboratory of HighPerformance Ceramics and Superfine Microstructure (SKL201908SIC).

\section{Availability of data and materials}

All data analyzed in this study are available in the main text and supporting information.

\section{Declarations}

\section{Ethics approval and consent to participate}

All animal experimental procedures were approved by the Ethical Committee of Zhongshan Hospital of Fudan University (B2019-136R2).

\section{Comment for publication}

The authors agreed to be published.

\section{Competing interests}

All authors declare that they have no competing interests.

\section{Author details}

${ }^{1}$ Department of Interventional Radiology, Zhongshan Hospital, Fudan University, Shanghai Institute of Medical Imaging, No. 180 Fenglin Road, Xuhui District, Shanghai 200032, China. ${ }^{2}$ Shanghai Engineering Technology Research Center for Pharmaceutical Intelligent Equipment, Shanghai Frontiers Science Research Center for Druggability of Cardiovascular noncoding RNA, Institute for Frontier Medical Technology, School of Chemistry and Chemical Engineering, Shanghai University of Engineering Science, No. 333 Longteng Road, Shanghai 201620, People's Republic of China. ${ }^{3}$ Institute for Technical and Macromolecular Chemistry, RWTH Aachen University, Worringerweg 2, 52074 Aachen, Germany. ${ }^{4}$ Institute of Translational Medicine, Shanghai University, Shanghai 200011 , People's Republic of China. ${ }^{5}$ School of Basic Medical Sciences, Shanghai University of Traditional Chinese Medicine, Shanghai, People's Republic of China. ${ }^{6}$ Department of Orthopaedics, Shanghai Key Laboratory for Prevention and Treatment of Bone and Joint Diseases, Shanghai Institute of Traumatology and Orthopaedics, Ruijin Hospital, Shanghai Jiao Tong University School of Medicine, 197 Ruijin 2nd Road, Shanghai 200025, People's Republic of China.

Received: 8 September 2021 Accepted: 8 December 2021

Published online: 20 December 2021

\section{References}

1. Bader JE, Voss K, Rathmell JC. Targeting metabolism to improve the tumor microenvironment for cancer immunotherapy. Mol Cell. 2020;78:1019-33.

2. Feng M, Jiang W, Kim B, Zhang CC, Fu YX, Weissman IL. Phagocytosis checkpoints as new targets for cancer immunotherapy. Nat Rev Cancer. 2019;19:568-86.

3. Yi M, Jiao D, Xu H, Liu Q, Zhao W, Han X, et al. Biomarkers for predicting efficacy of PD-1/PD-L1 inhibitors. Mol Cancer. 2018;17:129.

4. Gordon SR, Maute RL, Dulken BW, Hutter G, George BM, McCracken MN, et al. PD-1 expression by tumour-associated macrophages inhibits phagocytosis and tumour immunity. Nature. 2017;545:495-9.

5. Qin S, Xu L, Yi M, Yu S, Wu K, Luo S. Novel immune checkpoint targets: moving beyond PD-1 and CTLA-4. Mol Cancer. 2019;18:155.

6. Ribas A, Wolchok JD. Cancer immunotherapy using checkpoint blockade. Science. 2018;359:1350-5.

7. Chandran SS, Klebanoff CA. T cell receptor-based cancer immunotherapy: emerging efficacy and pathways of resistance. Immunol Rev. 2019;290:127-47.

8. O'Donnell JS, Teng M, Smyth MJ. Cancer immunoediting and resistance to T cell-based immunotherapy. Nat Rev Clin Oncol. 2019;16:151-67.

9. Rosenberg SA, Restifo NP. Adoptive cell transfer as personalized immunotherapy for human cancer. Science. 2015;348:62-8.

10. Gong J, Chehrazi-Raffle A, Reddi S, Salgia R. Development of PD-1 and PD-L1 inhibitors as a form of cancer immunotherapy: a comprehensive 
review of registration trials and future considerations. J Immunother Cancer. 2018;6:8.

11. Balachandran VP, Beatty GL, Dougan SK. Broadening the impact of immunotherapy to pancreatic cancer: challenges and opportunities. Gastroenterology. 2019;156:2056-72

12. Irvine DJ, Dane EL. Enhancing cancer immunotherapy with nanomedicine. Nat Rev Immunol. 2020;20:321-34.

13. Chmielewski M, Abken H. CART cells transform to trucks: chimeric antigen receptor-redirected $T$ cells engineered to deliver inducible IL-12 modulate the tumour stroma to combat cancer. Cancer Immunol Immunother. 2012;61:1269-77.

14. Wang X, Walter M, Urak R, Weng L, Huynh C, Lim L, et al. Lenalidomide enhances the function of CS1 chimeric antigen receptor-redirected T cells against multiple myeloma. Clin Cancer Res. 2018;24:106-19.

15. Chan WK, Suwannasaen D, Throm RE, Li Y, Eldridge PW, Houston J, et al. Chimeric antigen receptor-redirected CD45RA-negative T cells have potent antileukemia and pathogen memory response without graftversus-host activity. Leukemia. 2015;29:387-95.

16. Shi Y, Lammers T. Combining nanomedicine and immunotherapy Accounts Chem Res. 2019:52:1543-54

17. Zhang P, Zhai Y, Cai Y, Zhao Y, Li Y. Nanomedicine-based immunotherapy for the treatment of cancer metastasis. Adv Mater. 2019;31:1904156.

18. van der Meel R, Sulheim E, Shi Y, Kiessling F, Mulder WJM, Lammers T. Smart cancer nanomedicine. Nat Nanotechnol. 2019;14:1007-17.

19. Duan X, Chan C, Lin W. Nanoparticle-mediated immunogenic cell death enables and potentiates cancer immunotherapy. Angew Chem Int Ed Engl. 2019;58:670-80.

20. Šamec N, Zottel A, Videtič PA, Jovčevska I. Nanomedicine and immunotherapy: a step further towards precision medicine for glioblastoma. Molecules. 2020;25

21. Li J, Yu X, Jiang Y, He S, Zhang Y, Luo Y, et al. Second near-infrared photothermal semiconducting polymer nanoadjuvant for enhanced cancer immunotherapy. Adv Mater. 2020;2020:2003458.

22. Yong SB, Chung JY, Song Y, Kim J, Ra S, Kim YH. Non-viral nano-immunotherapeutics targeting tumor microenvironmental immune cells. Biomaterials. 2019;219:119401.

23. Muraoka D, Seo N, Hayashi T, Tahara Y, Fujii K, Tawara I, et al. Antigen delivery targeted to tumor-associated macrophages overcomes tumor immune resistance. J Clin Invest. 2019;129:1278-94.

24. Li S, Bennett ZT, Sumer BD, Gao J. Nano-immune-engineering approaches to advance cancer immunotherapy: lessons from ultra-pHsensitive nanoparticles. Acc Chem Res. 2020:53:2546-57.

25. Zeng Z, Zhang C, Li J, Cui D, Jiang Y, Pu K. Activatable polymer nanoenzymes for photodynamic immunometabolic cancer therapy. Adv Mater. 2021;33:2007247.

26. Wei P, Cornel EJ, Du J. Ultrasound-responsive polymer-based drug delivery systems. Drug Deliv Transl Res. 2021;11:1323-39.

27. Yu B, Choi B, Li W, Kim D. Magnetic field boosted ferroptosis-like cell death and responsive MRI using hybrid vesicles for cancer immunotherapy. Nat Commun. 2020;11:3637.

28. Chu H, Zhao J, Mi Y, Di Z, Li L. NIR-light-mediated spatially selective triggering of anti-tumor immunity via upconversion nanoparticle-based immunodevices. Nat Commun. 2019:10:2839.

29. Li X, Lovell JF, Yoon J, Chen X. Clinical development and potential of photothermal and photodynamic therapies for cancer. Nat Rev Clin Oncol. 2020;17:657-74

30. Liu Y, Bhattarai P, Dai Z, Chen X. Photothermal therapy and photoacoustic imaging via nanotheranostics in fighting cancer. Chem Soc Rev. 2019;48:2053-108.

31. Jiang $Q$, Liu Y, Guo R, Yao X, Sung S, Pang Z, et al. Erythrocyte-cancer hybrid membrane-camouflaged melanin nanoparticles for enhancing photothermal therapy efficacy in tumors. Biomaterials. 2019;192:292-308.

32. Li W, Yang J, Luo L, Jiang M, Qin B, Yin H, et al. Targeting photodynamic and photothermal therapy to the endoplasmic reticulum enhances immunogenic cancer cell death. Nat Commun. 2019;10:3349.

33. Peng J, Xiao Y, Li W, Yang Q, Tan L, Jia Y, et al. Photosensitizer micelles together with IDO inhibitor enhance cancer photothermal therapy and immunotherapy. Adv Sci (Weinh). 2018;5:1700891.

34. Chen Q, Xu L, Liang C, Wang C, Peng R, Liu Z. Photothermal therapy with immune-adjuvant nanoparticles together with checkpoint blockade for effective cancer immunotherapy. Nat Commun. 2016;7:13193.
35. Wang $T$, Wang $D$, Yu H, Feng B, Zhou F, Zhang $H$, et al. A cancer vaccinemediated postoperative immunotherapy for recurrent and metastatic tumors. Nat Commun. 2018:9:1532.

36. Huang L, Li Y, Du Y, Zhang Y, Wang X, Ding Y, et al. Mild photothermal therapy potentiates anti-PD-L1 treatment for immunologically cold tumors via an all-in-one and all-in-control strategy. Nat Commun. 2019;10:4871

37. Zhang X, An L, Tian Q, Lin J, Yang S. Tumor microenvironment-activated NIR-II reagents for tumor imaging and therapy. J Mater Chem B. 2020;8:4738-47.

38. Liu P, Wang Y, An L, Tian Q, Lin J, Yang S. Ultrasmall $W_{3-x}$ @gamma-polyI-glutamic acid nanoparticles as a photoacoustic imaging and effective photothermal-enhanced chemodynamic therapy agent for cancer. ACS Appl Mater Interfaces. 2018;10:38833-44.

39. Zhang Q, Guo Q, Chen Q, Zhao X, Pennycook SJ, Chen H. Highly efficient 2D NIR-II photothermal agent with fenton catalytic activity for cancer synergistic photothermal-chemodynamic therapy. Adv Sci. 2020;20:1902576.

40. Liu G, Zhu J, Guo H, Sun A, Chen P, Xi L, et al. Mo 2 C-derived polyoxometalate for NIR-II photoacoustic imaging-guided chemodynamic/photothermal synergistic therapy. Angew Chem Int Ed Engl. 2019;58:18641-6.

41. Ma Y, Zhang Y, Li X, Zhao Y, Li M, Jiang W, et al. Near-infrared II phototherapy induces deep tissue immunogenic cell death and potentiates cancer immunotherapy. ACS Nano. 2019;13:11967-80.

42. Li Y, Liu X, Pan W, Li N, Tang B. Photothermal therapy-induced immunogenic cell death based on natural melanin nanoparticles against breast cancer. Chem Commun. 2020;56:1389-92.

43. Gao G, Jiang YW, Guo Y, Jia HR, Cheng X, Deng Y, et al. Enzyme-mediated tumor starvation and phototherapy enhance mild-temperature photothermal therapy. Adv Funct Mater. 2020;30:1909391.

44. Zhen X, Xie C, Jiang Y, Ai X, Xing B, Pu K. Semiconducting photothermal nanoagonist for remote-controlled specific cancer therapy. Nano Lett. 2018;18:1498-505.

45. Wei H, Zhao Z, Wang Y, Zou J, Lin Q, Duan Y. One-step self-assembly of multifunctional DNA nanohydrogels: an enhanced and harmless strategy for guiding combined antitumor therapy. ACS Appl Mater Inter. 2019;11:46479-89.

46. Deng C, Zhang Q, Jia M, Zhao J, Sun X, Gong T, et al. Tumors and their microenvironment dual-targeting chemotherapy with local immune adjuvant therapy for effective antitumor immunity against breast cancer. Adv Sci (Weinh). 2019;6:1801868.

47. Tian Y, Wang X, Zhao S, Liao X, Younis MR, Wang S, et al. JQ1-loaded polydopamine nanoplatform inhibits c-MYC/programmed cell death ligand 1 to enhance photothermal therapy for triple-negative breast cancer. ACS Appl Mater Interfaces. 2019;11:46626-36.

48. Sun H, Feng M, Chen S, Wang R, Luo Y, Yin B, et al. Near-infrared photothermal liposomal nanoantagonists for amplified cancer photodynamic therapy. J Mater Chem B. 2020;8:7149-59.

49. Zhou F, Gao J, Xu Z, LiT, Gao A, Sun F, et al. Overcoming immune resistance by sequential prodrug nanovesicles for promoting chemoimmunotherapy of cancer. Nano Today. 2021;36:101025.

50. O'Neill LA, Bowie AG. The family of five: TIR-domain-containing adaptors in Toll-like receptor signalling. Nat Rev Immunol. 2007;7:353-64.

51. Kawai T, Akira S. TLR signaling. Semin Immunol. 2007;19:24-32.

\section{Publisher's Note}

Springer Nature remains neutral with regard to jurisdictional claims in published maps and institutional affiliations. 